\title{
Co-expression of cytokeratins and vimentin by highly invasive trophoblast in the white-winged vampire bat, Diaemus youngi, and the black mastiff bat, Molossus ater, with observations on intermediate filament proteins in the decidua and intraplacental trophoblast
}

\author{
N. K. Badwaik ${ }^{1}$, J. J. Rasweiler IV ${ }^{1 *}$ and F. Muradali ${ }^{2}$ \\ 'Department of Obstetrics and Gynecology, Cornell University Medical College, 1300 York Avenue, New York, NY 10021, USA; and \\ ${ }^{2}$ Ministry of Agriculture, Lands and Food Production, National Animal Disease Centre, Centeno, Republic of Trinidad and Tobago
}

\begin{abstract}
Histological and immunocytochemical studies of gravid reproductive tracts obtained from the white-winged vampire bat (Diaemus youngi) and the black mastiff bat (Molossus ater) have established that both species develop unusually invasive trophoblast. This is released by. the developing discoidal haemochorial placenta, expresses both cytokeratins and vimentin, and invades the myometrium and adjacent tissues (including the ovaries) via interstitial migration within the walls of maternal blood vessels. Hence, this trophoblast is noteworthy for the extent to which it undergoes an epithelial-mesenchymal transformation. In Molossus, it originates from the cytotrophoblastic shell running along the base of the placenta, is mononuclear, and preferentially invades maternal arterial vessels serving the discoidal placenta. This trophoblast may have a role in dilatation of these vessels when the discoidal placenta becomes functional. In Diaemus, the highly invasive trophoblast appears to originate instead from a layer of syncytiotrophoblast on the periphery of the placenta, is multinucleated, and vigorously invades both arterial and venous vessels. During late pregnancy, it becomes extensively branched and sends attenuated processes around many of the myometrial smooth muscle fibres. In view of its distribution, this trophoblast could have important influences upon myometrial contractility and the function of blood vessels serving the gravid tract. Other aspects of intermediate filament expression in the uteri and placentae of these bats are also noteworthy. Many of the decidual giant cells in Molossus co-express cytokeratins and vimentin, while the syncytiotrophoblast lining the placental labyrinth in Diaemus late in pregnancy expresses little cytokeratin.
\end{abstract}

\section{Introduction}

During pregnancy in many mammals, trophoblast invades the wall of the uterus. Humans have generally been viewed as somewhat unusual in this regard, because in normal pregnancies large numbers of extravillous cytotrophoblast cells penetrate as far as the inner third of the myometrium via both interstitial and endovascular routes. This is important physiologically, at least in part because some of these cells invade the walls of the spiral arterioles and are thought to be responsible for their dilatation. This enables the vessels to deliver increasing amounts of maternal blood to the placenta as pregnancy progresses. Such changes

${ }^{*}$ Correspondence.

Revised manuscript received 12 June 1998 frequently fail to occur in human pregnancies ending in spontaneous abortion, or complicated by pre-eclampsia, other hypertensive disorders and/or fetal growth retardation (Brosens et al., 1979; DeWolf et al., 1980, 1982; Gerretsen et al., 1981; Khong et al., 1986; Sheppard and Bonnar, 1988; Hustin et al., 1990; Khong and Sawyer, 1991; Pijnenborg, 1991, 1996; Pijnenborg et al., 1991).

Comparative studies of trophoblastic invasiveness in common experimental species have revealed both similarities and differences from the observations made in humans. The extravillous trophoblast of macaques is also quite invasive, progressing as far as the myometrial segments of the uteroplacental arteries. However, in the uteroplacental veins, invasion is limited to the vicinity of the cytotrophoblastic shell on the periphery of the placenta. Initial invasion of the arteries occurs preferentially via their 
lumina, whereas invasion of the veins occurs interstitially from the cytotrophoblastic shell. As pregnancy progresses, significant numbers of cytotrophoblast cells also penetrate the arterial walls. This is associated with extensive displacement of the smooth muscle layer and alterations of the extracellular matrix of the vessel wall. Although many cytotrophoblast cells invade the endometrial stroma close to the shell, in the myometrium this is limited to the vicinity of the uteroplacental arteries (Blankenship et al., 1993a,b; Blankenship and Enders, 1997a). In contrast, in humans, large numbers of cytotrophoblast cells invade the myometrium and many fuse to form giant cells (Pijnenborg et al., 1981). In baboons, trophoblastic invasion of the uteroplacental arteries is limited to their decidual segments. This involves endovascular migration and the penetration of the arterial walls by substantial numbers of cytotrophoblast cells. Interstitial trophoblast migration is limited and multinucleated giant cells are absent (Pijnenborg et al., 1996).

In cricetid and murid rodents, trophoblast does not normally invade the myometrium, except via an endovascular route along the uterine arteries (Pijnenborg et al., 1981; Carpenter, 1982). However, in guinea-pigs (a caviid rodent), trophoblast invades the uteroplacental arteries by both intramural and endovascular routes, and progresses at least as far as the mesometrial segments via the intramural route. The endovascular invasion is unusual since it does not commence until quite late in gestation (that is, about day 50 after mating) (Nanaev et al., 1995).

It is well established that trophoblast-maternal vascular interactions are important in the normal progression of human pregnancies, and that the patterns of trophoblastic invasion in the common small laboratory animals differ significantly from that of humans. This has prompted investigation of some species of bats for potentially useful new models. Bats are relatively closely related to humans (Novacek and Wyss, 1986) and have invasive trophoblast that participates in the formation of endotheliochorial or haemochorial placentae. Furthermore, they give birth to between one and four young (depending upon species), which are large relative to the weight of the mother, after gestation periods that are long for small mammals.

These studies have focused upon three species of neotropical bats: the short-tailed fruit bat (Carollia perspicillata) (family Phyllostomidae), the white-winged vampire bat (Diaemus youngi) (family Phyllostomidae), and the black mastiff bat (Molossus ater) (family Molossidae). The findings have established that highly invasive populations of trophoblast cells can develop during pregnancy in each species. These cells are unusual in the extent to which they undergo epithelial-mesenchymal transformations. This includes the ability to undergo lengthy migrations through the connective tissues of the reproductive tract and to express vimentin in addition to cytokeratins. Pronounced species differences have also been noted in the circumstances under which the invasive trophoblast develops, its cellular origin and its preferred routes of invasion. The observations for Carollia are therefore considered separately. As this is the first study that deals extensively with the female reproductive biology of Diaemus, some basic information on that subject will also be presented.

\section{Materials and Methods}

\section{Animals}

All bats were captured on the Caribbean island of Trinidad. The initial histological observations of the trophoblast of black mastiff bats (Molossus ater) were made on a large series of reproductive tracts obtained from captive bred animals killed at various intervals throughout pregnancy (Rasweiler, 1987, 1990, 1991a). The animals were housed in a room with a controlled light cycle ( $12 \mathrm{~h}$ light: $12 \mathrm{~h}$ dark), with the dark phase set to commence at $16: 00 \mathrm{~h}$, and were fed a diet of mealworms. The mealworms were either fattened on a supplemented medium and sprayed with a multivitamin preparation, or were sprayed with the multivitamins and then dusted with calcium carbonate. When it became obvious that immunocytochemical studies were needed to confirm the identification of some of the trophoblast, an additional 13 pregnant animals were collected from the reproductively synchronized wild population on 29 April 1994 and 29 April 1995. The fetuses of these animals had crown-rump lengths of $24.0-33.5 \mathrm{~mm}$.

The white-winged vampire bats (Diaemus youngi) were all collected in the wild between January 1990 and June 1992 by mist netting, usually around domestic fowl (which are preyed upon by Diaemus), in rural areas of Trinidad. Most females $(30 / 32)$ were processed within $24 \mathrm{~h}$ of capture. The remaining two females were held in captivity for 3 or 4 days. These two bats were housed in a wire mesh cage placed underneath another cage containing a live chicken. This enabled the bats to feed on blood (their only food) from the toes of the chickens while the birds slept. A different chicken was used each night. The bats were also offered water ad libitum. This procedure for feeding Diaemus was not painful for the chickens and did not cause them any lasting harm. This has been confirmed by measurements of total protein levels and packed cell volumes in blood collected from chickens that had been used to feed captive Diaemus once per week in another study conducted at Cornell University (F. W. Quimby, personal communication). The relatively innocuous nature of Diaemus feeding upon chickens has also been described in detail by Winter and Coen (1997). Diaemus requires the frequent consumption of avian blood, cannot survive long term on defribrinated mammalian blood, and cannot be introduced into captivity reliably using blood offered in dishes (Goodwin and Greenhall, 1961; Winter and Coen, 1997; F. Muradali, unpublished; F. W. Quimby, personal communication).

\section{Timing of reproductive stages}

A single male with prominent testes was added to each group of 8-15 females to breed the Molossus maintained in captivity. On the mornings after introduction of the male, a small quantity of distilled water was aspirated into the vagina of each female with a microeyedropper and was checked for spermatozoa as described by Rasweiler (1987).

Most female Molossus were receptive to the males, at least periodically, over extended periods. They also exhibited a 
prolonged period of about 10-50 days during which spermatozoa were present in the vaginal aspirates almost every day. Mated females were killed between 09:00 and 12:00 $\mathrm{h}$ at various intervals after the onset of this extended period of sperm-positive vaginal aspirates to obtain representative stages of pregnancy.

Both Molossus and Diaemus were given overdoses of sodium pentobarbital (approximately $90 \mathrm{mg} \mathrm{kg}^{-1}$ body mass), administered by intraperitoneal injection, and then decapitated when fully anaesthetized to collect the reproductive organs.

\section{Measurements of the reproductive tract and conceptus}

In Molossus, the greatest diameter of the right uterine horn (which normally carries the conceptus) was measured at the time of dissection. During early pregnancy, the dimensions of histologically sectioned uterine blastocysts were measured so as to include the main body of trophoblast, but not any attenuated extensions of the latter into the decidua. When conceptuses could readily be dissected out of the uterus, they were weighed and their crown-rump lengths were recorded.

In Diaemus, the greatest diameter (transverse dimension) of the largest uterine horn, or of the uterus as a whole, was measured after fixation. In this species, the horns disappear and the uterus assumes a simplex appearance as pregnancy progresses. This is retained in at least recently postpartum females. The major and minor axes of sectioned implanted blastocysts in Diaemus were measured so as to include the limits of the cytotrophoblastic shell, but not invasive trophoblast that had penetrated the uterine wall beyond the shell. The crown-rump length and mass of each Diaemus fetus that could be dissected out were also measured.

\section{Histological procedures}

The tracts from the Molossus were fixed in Zenker's fluid for 8-12 $\mathrm{h}$ and then processed to paraffin wax for routine histological examination as described previously (Rasweiler, 1990; Rasweiler and Badwaik, 1997). The Diaemus tracts were fixed in Bouin's solution for at least 2-3 days and then stored in $70 \%$ ethyl alcohol. The specimens were then washed in multiple changes of $70 \%$ ethyl alcohol, dehydrated through graded ethyl alcohols, cleared overnight in warm cedar wood oil $\left(37^{\circ} \mathrm{C}\right)$ and then by passage through four changes of Histosol (National Diagnostics Inc., Atlanta, GA), and embedded in paraffin wax. The tracts, or the regions of the tracts of particular interest, were then serially sectioned (in a frontal plane) at $6 \mu \mathrm{m}$. The sections were stained with haematoxylin and eosin, Masson's trichrome procedure, or by the periodic acid-Schiff (PAS) technique. Some sections of each tract were incubated for $1 \mathrm{~h}$ at $37^{\circ} \mathrm{C}$ in $0.1 \%(\mathrm{w} / \mathrm{v}) \alpha-$ amylase (1,4- $\alpha$-D-glucan-glucanohydrolase; Sigma Chemical Company, St Louis, MO) dissolved in a $0.02 \mathrm{~mol}$ phosphate buffer $1^{-1}$ ( $\mathrm{pH} \mathrm{6.0)}$ to remove any glycogen before they were processed according to the PAS procedure. Parallel sections were incubated under similar conditions in the buffer alone and were then stained.

\section{Immunocytochemistry}

Immunocytochemical methods were used to confirm some of the cell identifications in this study. In Diaemus, these were performed on sections of the tracts that had been fixed in Bouin's solution for routine histology. In Molossus, gravid uteri were obtained from animals collected in the field and were immersed in cold Zamboni's fluid. The discoidal placenta, adjacent portion of the uterine wall and the right ovary were then dissected free from the remainder of the tract and fixed for $48 \mathrm{~h}$ in the same solution. The specimens were washed and transported in cold $0.1 \mathrm{~mol} \mathrm{PBS} \mathrm{l}^{-1}$ ( $\left.\mathrm{pH} 7.4\right)$. Upon arrival in New York, the specimens were dehydrated through graded ethyl alcohols, cleared overnight in warm cedar wood oil $\left(37^{\circ} \mathrm{C}\right.$ ) and then by Histosol (National Diagnostics Inc., Atlanta, GA), and embedded in paraffin wax.

Sections of the embedded specimens were cut at a thickness of $6 \mu \mathrm{m}$ and mounted on slides treated with a $2 \%$ solution $(\mathrm{v} / \mathrm{v})$ of 3-aminopropyltriethoxysilane (Sigma Chemical Company, St Louis, MO) in acetone. After deparaffinization and rehydration, endogenous peroxidase activity in the sections was blocked by $30 \mathrm{~min}$ incubation with $3 \%(\mathrm{v} / \mathrm{v})$ hydrogen peroxide in methanol. The sections were then treated with $0.025-0.1 \%(\mathrm{w} / \mathrm{v})$ bovine pancreatic trypsin (Calbiochem, San Diego, CA) in $0.1 \%(w / v)$ aqueous $\mathrm{CaCl}_{2}$ for $2-8 \mathrm{~min}$ at $37^{\circ} \mathrm{C}$ to unmask antigenic sites, washed in running tap water, and rinsed with PBS.

The slides were positioned on Sequenza cover plates (Shandon-Lipshaw, Pittsburgh, PA) and loaded into Sequenza slide racks. The Sequenza system facilitated subsequent steps in the staining procedure and reduced the use of expensive reagents. An avidin-biotin blocking kit was then used to prevent non-specific binding of biotin-avidin system reagents (Vector Laboratories, Burlingame, CA). The slides were rinsed with PBS and then with PBS containing $1 \%(\mathrm{w} / \mathrm{v})$ fatty acid free BSA. PBS containing $1 \%$ fatty acid free BSA was also used for diluting the blocking serum, primary and secondary antibodies, and components of the immunoperoxidase kit (see below). All reagents and substrate solutions used in these steps were prepared with glass distilled water.

Non-specific antibody binding was minimized by treatment of the sections with normal serum from the source of the secondary antibody for $30 \mathrm{~min}$. The sections were then incubated overnight at $4^{\circ} \mathrm{C}$ with the primary antibody. Antibodies used included the following: CAM 5.2 (Becton Dickinson, San Jose, CA), a mouse monoclonal directed against human cytokeratins 8 and 18; AE1/AE3 (Zymed Laboratories Inc., South San Francisco, CA), a mouse monoclonal cocktail directed against a variety of keratins of the acidic and basic subfamilies; a mouse monoclonal directed against human leiomyomal desmin (Zymed Laboratories Inc.); a mouse monoclonal directed against pig lens vimentin (Zymed Laboratories Inc.); and a rabbit polyclonal directed against human factor VIII-related antigen (Zymed Laboratories Inc.). After this and each subsequent step the sections were rinsed with PBS. The sections were then incubated for $30 \mathrm{~min}$ with a biotinylated anti-mouse secondary antibody (Vector Laboratories, 
Burlingame, CA), for a further $30 \mathrm{~min}$ with the enzyme conjugate in the Vectastain Elite ABC Kit (Vector Laboratories), and finally for $10 \mathrm{~min}$ in a solution of diaminobenzidine and hydrogen peroxide to develop a coloured reaction product at sites occupied by the antigens of interest. Negative controls were performed by replacing the primary antibody with an isotype matched irrelevant antibody at the same concentration for the monoclonal antibodies, or purified normal rabbit immunoglobulin at a similar concentration for the polyclonal antibodies directed against factor VIII-related antigen. Some sections were counterstained with Gill's haematoxylin.

\section{Results}

\section{Chorioallantoic placentae of Molossus}

Molossus is unusual in developing two different chorioallantoic placentae. The first, a diffuse endotheliochorial placenta, lines most of the right uterine horn and is functional in mid-pregnancy. The second, a discoidal haemochorial placenta, always forms at the cranial end of the same horn (centered on the uterotubal junction) and is functional in late pregnancy. The development of both placentae involves the invasion of trophoblast almost to the endometrial-myometrial border and is associated with decidualization of the endometrial stroma. Placentation in Molossus has been described elsewhere in detail with accompanying orientation diagrams (Rasweiler, 1990, 1991a, 1992).

\section{Highly invasive trophoblast in Molossus}

As gestation progresses in Molossus, a population of cytotrophoblast that is unusually invasive penetrates the myometrium via the walls of the uteroplacental vessels serving the discoidal placenta. This cytotrophoblast exhibits a preference for the uteroplacental arteries (although some cytotrophoblast cells were occasionally seen in the veins), migrates between the endothelium and tunica media, and is rich in glycogen (Fig. 1a). The cytotrophoblastic shell at the base of the discoidal placenta, which gives rise to the invasive trophoblast, is also rich in glycogen (Rasweiler, 1991a). Endovascular migration of trophoblast into the myometrium or beyond was not observed in Molossus.

The identification of these cells as cytotrophoblast was confirmed by intermediate filament protein immunocytochemistry. They were reactive with the anticytokeratin antibody preparations AE1/AE3 and CAM 5.2 (Fig. 1b,d), but were negative for desmin. Cytotrophoblast in a subendothelial position was also generally positive for vimentin (Fig. 1c,e).

Although the reaction with the anti-vimentin antibodies was only moderate in the wall of uteroplacental arteries entering the base of the placenta (Fig. 1c), this was clearly greater than background staining. Background staining was not a problem in these studies. Furthermore, the labyrinth of the discoidal haemochorial placenta of Molossus is lined by cytotrophoblast (Fig. 2a), and this cytotrophoblast was negative for vimentin (Fig. 2b) on the same section shown in Fig. 1c. In addition, uteroplacental vessels at the base of the placenta are lined by a stratified endothelium that is sometimes intermingled with scattered cytotrophoblast cells (Fig. 2a,b) or larger patches of cytotrophoblast, which in some areas constitutes the only epithelial lining for part of the vessel. This cytotrophoblast was usually negative for vimentin. The only exception was at the base of the placenta, immediately before the vessels pass into the decidua. Here, cytotrophoblast within the stratified endothelium expressed some vimentin. Within the same section, the concentration of vimentin generally appeared to be greater as trophoblast cells were examined further out in the uterine wall.

Molossus is the first species in which a stratified endothelium has been observed. The cells were found to be negative for cytokeratin and desmin, positive for vimentin and sometimes reacted with antibodies directed against factor VIII-related antigen (a recognized marker for endothelial cells). Furthermore, they contained abundant glycoprotein-rich granules similar to those present in endothelial cells lining the same vessels earlier in pregnancy. These endothelial cells are also highly proliferative earlier in pregnancy (Rasweiler, 1991a).

The cytotrophoblast that migrates away from the discoidal placenta in Molossus is highly invasive. Cytotrophoblast cells were observed in the walls of blood vessels in the broad ligament, ipsilateral oviduct and right ovary (Fig. 2c). The cytotrophoblast cells in these locations expressed both cytokeratins and vimentin (Fig. 2d,e), but were negative for desmin.

\section{Intermediate filament protein expression by the decidual cells in Molossus}

The decidual giant cells of Molossus also reacted with anticytokeratin antibodies in the monoclonal mix AE1 / AE3 (Fig. 1b). These cells have distribution and other cytological characteristics (for example, being multinucleated with a prominent glycoprotein-rich pericellular 'capsule') that are typical of decidual cells in this species. Decidual cells with such characteristics were seen in the non-gravid left uterine horn of pregnant Molossus and the spontaneously decidualized uteri of non-pregnant animals. Trophoblast is normally absent in both situations (Rasweiler, 1990, 1991a,b). In addition, the decidual cells of this bat reacted with antibodies directed against vimentin (Fig. 1c) and sometimes desmin.

\section{Reproductive condition and seasonal distribution of Diaemus specimens}

The Diaemus were collected over 30 months, with specimens representing all months of the year (Table 1). Animals classified as having active or preovulatory tracts exhibited stimulation (vacuolation) of the oviductal secretory cells that is typical of the same stage in related phyllostomid and noctilionid bats (Rasweiler, 1972, 1977, 
Table 1. Reproductive condition of field-caught white-winged vampire bats, Diaemus youngi

\begin{tabular}{|c|c|c|c|c|c|c|}
\hline \multirow[b]{2}{*}{$\begin{array}{l}\text { Month of } \\
\text { capture }\end{array}$} & \multirow[b]{2}{*}{$\begin{array}{l}\text { Number } \\
\text { of } \\
\text { specimens }\end{array}$} & \multicolumn{5}{|c|}{ Reproductive condition } \\
\hline & & $\begin{array}{l}\text { Non-active } \\
\text { or immature }\end{array}$ & $\begin{array}{c}\text { Active or } \\
\text { preovulatory }\end{array}$ & $\begin{array}{l}\text { Early pregnancy } \\
\text { (stage of embryo) }\end{array}$ & $\begin{array}{l}\text { Advanced } \\
\text { pregnancy } \\
\text { (fetal crown- } \\
\text { rump length) }\end{array}$ & $\begin{array}{l}\text { Recently } \\
\text { postpartum } \\
\text { and/or non- } \\
\text { pregnant }\end{array}$ \\
\hline January & 4 & - & - & $\begin{array}{l}1 \text { PP (implanted blastocyst) } \\
1 \text { PP (implanted blastocyst) } \\
1 \text { PP (primitive streak stage) }\end{array}$ & $1(15.0 \mathrm{~mm})$ & - \\
\hline February & 1 & 1 & - & - & - & - \\
\hline March & 2 & - & - & 1 (primitive streak stage) & $1(22.0 \mathrm{~mm})$ & - \\
\hline April & 4 & 1 & . & 1 (somite stage) & $2(28.0-28.5 \mathrm{~mm})$ & - \\
\hline May & 3 & 2 & - & - & $1(36.3 \mathrm{~mm})$ & - \\
\hline June & 1 & - & - & - & $1(20.0 \mathrm{~mm})$ & - \\
\hline July & 4 & 1 & - & - & $1(20.9 \mathrm{~mm})$ & $2 P^{*}+$ \\
\hline August & 3 & 2 & $1 \mathrm{PP}^{*}+$ & - & - & - \\
\hline September & 4 & 2 & $\begin{array}{c}1 \\
1 \mathrm{GF}\end{array}$ & - & - & - \\
\hline October & 1 & 1 & - & - & - & - \\
\hline November & 3 & - & $\begin{array}{l}1 \mathrm{GF} \\
1 \mathrm{PPt}\end{array}$ & $\begin{array}{l}1 \text { PP (implanted blastocyst, } \\
\text { early amniogenesis) }\end{array}$ & - & - \\
\hline December & 2 & - & - & 1 PP (oviductal embryo) & - & $1 \mathrm{PP}^{*}+$ \\
\hline
\end{tabular}

GF, Graafian follicle; PP, recently postpartum.

*Non-menstrual blood and other cellular debris present in uterine lumen.

tHighly invasive trophoblast from previous pregnancy still present in reproductive tract.

1993; Bonilla and Rasweiler, 1974), and sometimes had large Graafian follicles. Two of the preovulatory animals must have recently given birth because they had enlarged uteri, blood vessels serving the reproductive tracts that had undergone changes typical of those seen during pregnancy in this species, blood and other cellular debris in the uterine lumen (one animal), and still had some invasive trophoblast in their tracts. The vascular changes included the deposition of glycoproteins in the vessel walls (especially of the arteries), intimal thickening of the arterial vessels, and some fibrosis of the walls of both arteries and veins. Many of the females carrying early embryos had tracts with similar vascular modifications persisting from previous pregnancies. These were less pronounced in the postpartum tracts carrying implanted blastocysts or primitive streak stage embryos. Three non-pregnant, recently parturient females showed no signs of preovulatory stimulation of their tracts. Seven females were in advanced pregnancy and carried fetuses of 15.0-36.3 mm crown-rump length.

Preovulatory females were captured from August to November, early pregnant females from November to April, advanced pregnant females from January to July, and recently postpartum animals from July to January.

\section{Characteristics of trophoblast associated with early postimplantation embryos in Diaemus}

The earliest blastocyst found in Diaemus was interstitially implanted in the left uterine horn and measured about $740 \mu \mathrm{m} \times 950 \mu \mathrm{m}$. The uterus of this species is partially bicornuate with a large body and very short horns. The implantation site in the earliest specimen was at a mid-horn location on the anti-mesometrial side. The inner cell mass was oriented anti-mesometrially, was discoidal and did not show any evidence of the onset of amniogenesis. At this stage, only a preplacenta (chorionic placenta) had formed (Fig. 3a). This consisted of maternal vascular spaces lined by syncytiotrophoblast and scattered rounded endothelial cells underlaid by syncytiotrophoblast. Abundant mitotically active cytotrophoblast cells were present between the syncytiotrophoblast-lined vascular spaces. A continuous layer of syncytiotrophoblast was also present on the periphery of the region occupied by the early placental labyrinth. This, in turn, was surrounded by a broad shell of cytotrophoblast which abutted the decidua. The identification of these types of cell was confirmed by immunocytochemically staining uterine sections containing slightly more advanced embryos for intermediate filament proteins (see below).

Tongues of syncytiotrophoblast could be seen extending out from the early preplacenta around maternal vessels serving the implantation site (Fig. 3a), and some of the trophoblast had already penetrated the myometrium beneath the implantation site via an interstitial (perivascular) route. This was identified as trophoblast because the cells were larger than those normally found in vessel walls, were frequently multinucleated and were positive for cytokeratin. Furthermore, their nuclei were generally more vesicular and euchromatic and had more prominent nucleoli than those of the cells that usually constitute the walls of blood vessels. With the exception of recently postpartum bats, cells with similar characteristics were not observed around the myometrial blood vessels of non-pregnant animals. In 

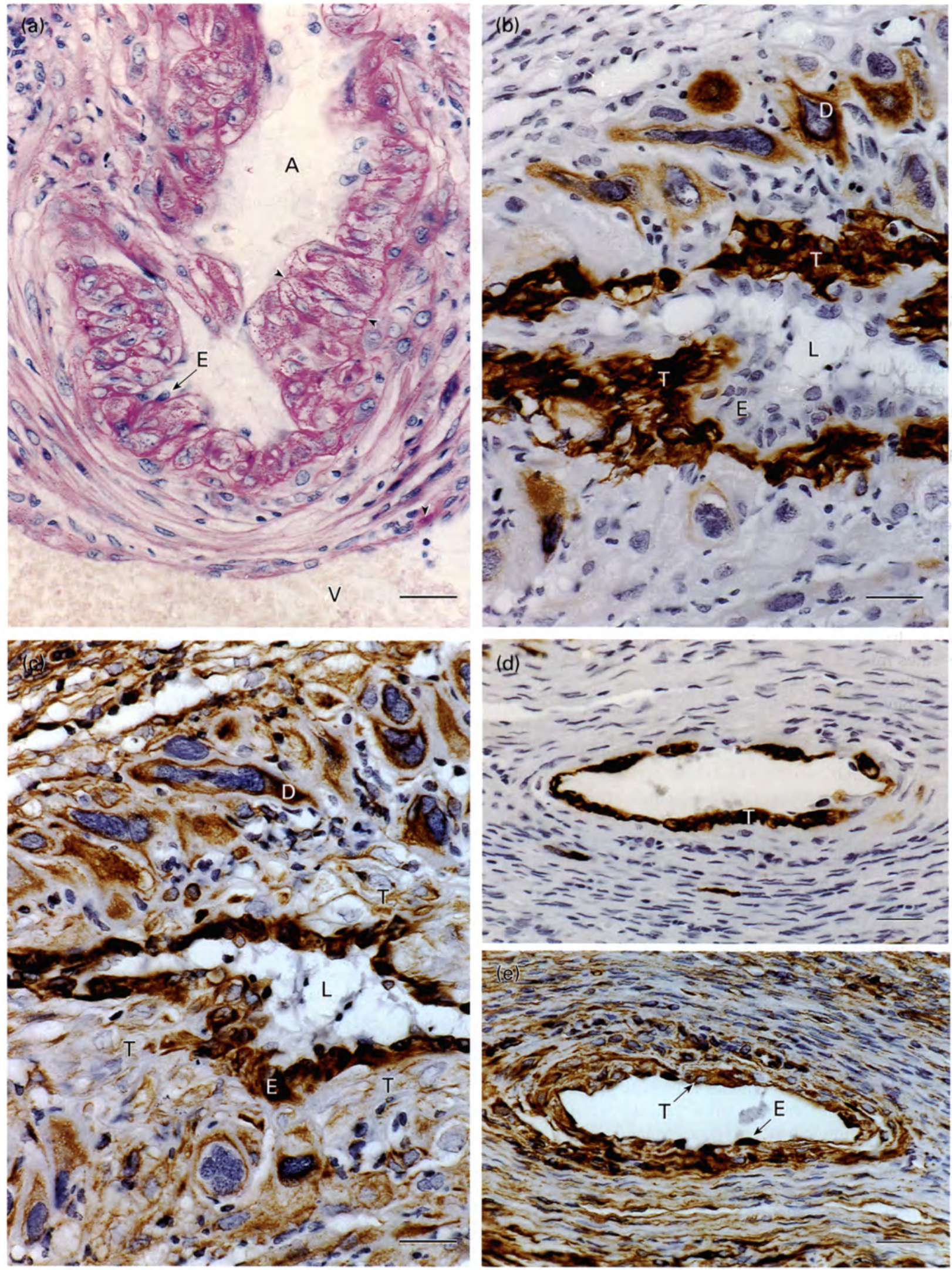

Fig. 1. Sections from gravid reproductive tracts of black mastiff bats, Molossus ater. (a) Section of myometrium, stained with periodic acid-Schiff (PAS) and haematoxylin, showing segments of arterial and venous vessels serving the discoidal haemochorial placenta of a female carrying a 27:1 mm fetus (advanced pregnancy). Many cytotrophoblast cells containing PAS-positive glycogen occupy a 
another bat carrying a larger blastocyst $(1225 \mu \mathrm{m} \times 1300 \mu \mathrm{m})$ that still had a solid inner cell mass, trophoblast had invaded some blood vessels close to the serosal surface of the uterus (Fig. 3b).

One female carried a blastocyst $(2.30 \mathrm{~mm} \times 2.82 \mathrm{~mm})$ in which amniogenesis had been initiated. As in related species, this occurs by cavitation (Rasweiler, 1974; Rasweiler and Badwaik, 1996; Badwaik et al., 1997). Many of the myometrial vessels beneath the placenta had a single layer of highly invasive trophoblast immediately adjacent to the endothelial lining. However, in some areas, this perivascular trophoblast was multilayered and appeared to be streaming away from the preplacenta because it consisted of elongated masses with a similar orientation.

Two females carried primitive streak stage embryos and one a somite stage embryo. In these, trophoblast had extensively infiltrated the myometrium at the cranial end of the gravid horn. Every vessel larger than a capillary contained trophoblast in its wall and, in some, it was multilayered (Figs 4 and 5a). This made it impossible to readily distinguish arteries from veins. This highly invasive trophoblast was reactive with antibody preparations directed against cytokeratins (AE1/AE3 and CAM 5.2) and vimentin (Fig. 5b-d). It did not react with antibodies directed against desmin. In serial sections, it was easy to trace an unbroken stream of this trophoblast along the larger blood vessels back to its apparent origin from the trophoblastic face of the placenta (see below). This population of trophoblast is referred to as 'highly' invasive because it ultimately penetrates much further than non-cancerous trophoblast in most other well-studied mammals. In addition, this terminology distinguishes it from the invasive intraendometrial trophoblast that interacts with the decidua during interstitial implantation and the formation of a discoidal haemochorial placenta in Diaemus.

Considerable evidence suggests that the highly invasive trophoblast, which is non-mitotic, arises from the syncytial face of the developing placenta. When it first leaves the placenta, this trophoblast consists largely of parallel elongated multinucleated strands (Fig. 5e). These always appeared to come directly off the syncytial face and never from the cytotrophoblastic shell. In fact, in histological sections, the latter had a tendency to cleave free from the invasive trophoblast close to the preplacenta. The size and clustering of the nuclei within the trophoblastic strands was also very similar to that observed within the syncytial face of the placenta, and different from that in any of the cytotrophoblast. In all specimens examined, from the earliest implanted blastocyst to the somite stage embryo, the syncytial face appeared continuous (that is, unbroken by cytotrophoblast). Cytotrophoblast within the preplacenta was mitotically active and may fuse with the syncytial face, or possibly continguous areas of syncytiotrophoblast within the placenta, to replenish the face as masses of invasive trophoblast are released. Trophoblast that was apparently streaming away from the syncytial face initially contained only moderate amounts of cytokeratins (Fig. 5e) as were observed in the syncytiotrophoblast of the preplacenta. However, cytotrophoblast in the placenta and cytotrophoblastic shell was always rich in these proteins (Fig. 6a). Vimentin was also expressed by the syncytial face of the placenta, the invasive trophoblast and the cytotrophoblastic shell (Figs $5 \mathrm{f}$ and $6 \mathrm{c}$ ). However, relatively little vimentin was expressed by the portion of the cytotrophoblastic shell immediately adjacent to the invasive trophoblast. Syncytiotrophoblast in the placental labyrinth was negative for vimentin.

The syncytial face of the developing placenta was also rich in glycoproteins (Fig. $5 \mathrm{~g}$ ). This may be related to the glycoprotein-rich linear structure observed running close to the luminal edge of the syncytiotrophoblast in adjacent maternal vascular spaces. The latter presumably corresponds to the intrasyncytial lamina, a basal lamina-like layer that is penetrated and engulfed by ectoplasmic processes of the syncytiotrophoblast. This has been observed ultrastructurally in the placental labyrinth of other bats, including the closely related common vampire bat, Desmodus rotundus (Björkman and Wimsatt, 1968; Enders and Wimsatt, 1968; Badwaik and Rasweiler, 1998).

When elongated trophoblastic masses were observed leaving the placenta, vimentin was typically concentrated at their front and back ends. Although it was common to see between four and six closely packed nuclei within a mass, the ends generally were not observed simultaneously (Fig. $5 b, f)$. The lengths of the masses therefore remain uncertain.

\section{Maternal endothelial cells within the developing placenta and nature of the interhaemal barrier late in gestation}

From early amniogenesis through to the somite stage of development, maternal endothelial cells were absent from some portions of the labyrinth, particularly close to the embryonic and maternal faces of the developing discoidal

subendothelial position (between arrowheads) in the wall of the arterial vessel. Only a single trophoblast cell (arrowhead) is evident in the wall of the venous vessel. (b) Section of an arterial vessel at the base of the discoidal haemochorial placenta of a female carrying a $28 \mathrm{~mm}$ fetus (advanced pregnancy), stained for cytokeratins with antibody mix AE1/AE3 and counterstained with haematoxylin. Both cytotrophoblast in a subendothelial position and decidual giant cells are positive for cytokeratin. The maternal endothelial cells are hypertrophied. (c) Section of arterial vessel adjacent to that shown in (b), stained immunocytochemically for vimentin and counterstained with haematoxylin. Cytotrophoblast within the vessel wall contains some vimentin, as do the decidual giant cells and hypertrophied maternal endothelial cells. (d) Section of arterial vessel further out in the myometrium of the same uterus shown in (b) and (c), stained immunocytochemically for cytokeratins with antibody mix AE1/AE3 and counterstained with haematoxylin. Cytokeratin-positive cytotrophoblast cells form almost a complete subendothelial layer in the vessel wall. (e) Section of arterial vessel adjacent to that shown in (d), stained immunocytochemically for vimentin and counterstained with haematoxylin. Cytotrophoblast cells within the vessel wall are stained more intensely for vimentin than those close to the placenta in the same section (see part (c)). A, arterial vessels; D, decidual giant cells; E, maternal endothelial cells; L, lumen of vessel; $T$, cytotrophoblast; $V$, venous vessels. Scale bars represent $25 \mu \mathrm{m}$. 

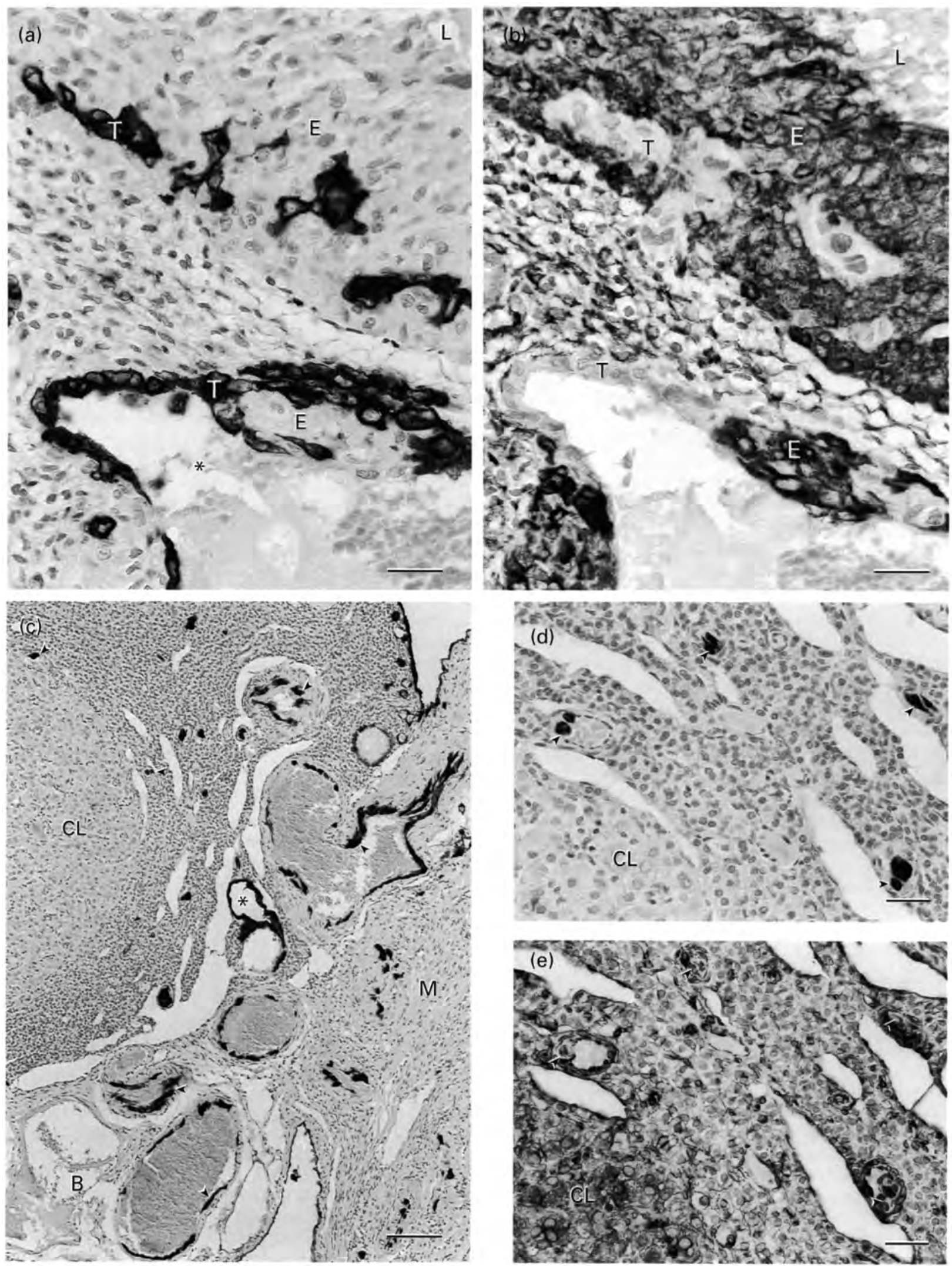

Fig. 2. Sections from gravid reproductive tracts of black mastiff bats, Molossus ater. (a) Section through the base of the discoidal haemochorial placenta from a female carrying a $28 \mathrm{~mm}$ fetus stained immunocytochemically for cytokeratins with antibody mix AE1/ AE3 and counterstained with haematoxylin. Uteroplacental vessels in this region are lined by a cytokeratin-negative stratified 
placenta. However, rounded-up (non-squamous) vimentinpositive endothelial cells were abundant throughout much of the labyrinth (Figs $6 \mathrm{c}$ and 7) and occasionally these were congregated in masses in some portions of the labyrinth near the maternal face. These endothelial cells were underlaid by syncytiotrophoblast. Scattered endothelial cells were still present in the chorioallantoic placenta serving a $22 \mathrm{~mm}$ fetus, but by this stage much of the interhaemal barrier had apparently become haemodichorial (Fig. 8). This is known to occur in the closely related Desmodus (Björkman and Wimsatt, 1968), but requires ultrastructural confirmation for Diaemus. The barrier included a layer of cytokeratinpoor syncytiotrophoblast lining the maternal vascular spaces and an adjacent layer of cytokeratin-rich cytotrophoblast (Fig. 8).

\section{Intermediate filament protein expression by the decidua of Diaemus}

Immunocytochemical staining confirmed the identification of decidual cells. At the primitive streak and somite stages, decidual cells were negative for cytokeratin but positive for desmin (Fig. 6a,b). They also expressed vimentin. However, the reactive protein was often concentrated in a limited part of the decidual cells, and therefore not every cell appeared to be stained in the sections. At the somite stage, the greatest number of strongly reactive cells were adjacent to the lateral edges of the developing chorioallantoic placenta (Fig. 6c). The arrangement beneath the centre of the placenta was further complicated by the fact that some of the trophoblast cells had extended processes in between the decidual cells (Fig. 6a). These processes were positive for both vimentin and cytokeratin.

\section{Heterogeneous appearance and extent of dispersal of highly invasive trophoblast in Diaemus}

The appearance of the perivascular invasive trophoblast became much more heterogeneous moving away from the placenta. In some areas, it consisted predominantly of elongated multinucleated strands (Fig. 6d), whereas in others the trophoblast cells were larger, more rotund, and surrounded by an abundance of glycoproteins (Fig. 6e). In these latter areas, the least differentiated trophoblast tended to be on the periphery (that is, furthest removed from the lumina of the blood vessels).

Three tracts were examined that contained large fetuses (28-36.5 mm crown-rump length). The largest of these weighed $9.75 \mathrm{~g}$, was furred, and was carried by a female that weighed $45.45 \mathrm{~g}$ with the fetus in utero. In comparison, seven females that carried early embryos (cleaving oviductal embryo to somite stage) weighed $33.00-39.45 \mathrm{~g}$ (mean $\pm \mathrm{SD}=$ $36.42 \pm 2.17 \mathrm{~g}$ )

In these and recently postpartum tracts, the trophoblast was much more widely dispersed than early in pregnancy. Large amounts were observed in the mesenteries of the tract and some was even present in the ovaries (Fig. 6f). Trophoblast remained abundant within the walls of major blood vessels (arterial and venous) serving the reproductive tract, both within the uterus and running in the mesenteries of the tract (Fig. 9a,b). In the larger arterial vessels, much of the trophoblast was on the outside of the tunica media. This suggests that as the invasion progresses into larger arterial vessels, the trophoblast may be diverted from an intimal to an adventitial pathway. The cells in these various locations were undoubtedly trophoblast because they were positive for cytokeratin, negative for desmin, had large euchromatic nuclei with prominent nucleoli, and were frequently multinucleated (Fig. 9c).

The trophoblast in the ovaries also developed dendritic processes (Fig. 6f) similar to those of the myometrial trophoblast (see below) and had a very uneven and largely perivascular distribution. This trophoblast was moderately abundant in some regions of the cortex and medulla (for example, particularly close to the hilus) but was absent from adjacent and apparently similar areas. This observation provides additional evidence that these cells are not a normal non-trophoblastic component of the ovaries. The only other cytokeratin-positive components of the ovaries were the germinal epithelium and the rete ovarii.

As in earlier stages (Fig. 2b), the highly invasive trophoblast continued to express vimentin late in pregnancy and immediately after parturition. Because this trophoblast was distributed in the form of a complex maze in the walls of larger blood vessels, the limits of the cytoplasmic masses could not be determined readily (Fig. 9c). It is possible that

\footnotetext{
maternal endothelium that is sometimes intermingled with cytotrophoblast cells. Smaller passageways $\left(^{*}\right)$ leading into the placental labyrinth are lined by a monolayer of cytotrophoblast with occasional patches of stratified endothelial cells. (b) Section through the base of the discoidal haemochorial placenta adjacent to that shown in (a), stained immunocytochemically for vimentin and counterstained with haematoxylin. The stratified maternal endothelium was positive for vimentin. Although the cytotrophoblast shown here was negative for vimentin, that present elsewhere in the same section in a subendothelial location was positive for vimentin (see Fig. 1c,e). (c) Section of ovary containing the corpus luteum of pregnancy, broad ligament and myometrium of the uterus adjacent to the discoidal placenta from a female carrying a $30.5 \mathrm{~mm}$ fetus (advanced pregnancy). This was stained immunocytochemically for cytokeratins with antibody mix AE1/AE3 and counterstained with haematoxylin. Cytotrophoblast (arrowheads) is present in the walls of arterial vessels in all three regions, including some close to the corpus luteum. An inpocketing of cytokeratin-positive mesothelium ( ${ }^{*}$ ) is also evident. (d) Higher magnification view of the ovarian section shown in (c). Cytokeratin-positive cytotrophoblast (arrowheads) is visible in the walls of some arterioles. (e) Section of ovary adjacent to that shown in (d), stained immunocytochemically for vimentin and counterstained with haematoxylin. Many of the cytotrophoblast cells were reactive for both cytokeratins (see part (d)) and vimentin (arrowheads). B, broad ligament; CL, corpus luteum; E, stratified maternal endothelium; L, Iumen of uteroplacental vessel; M, myometrium; T, cytotrophoblast. Scale bars represent (a,b,d,e) $25 \mu \mathrm{m}$ and (c) $100 \mu \mathrm{m}$.
} 

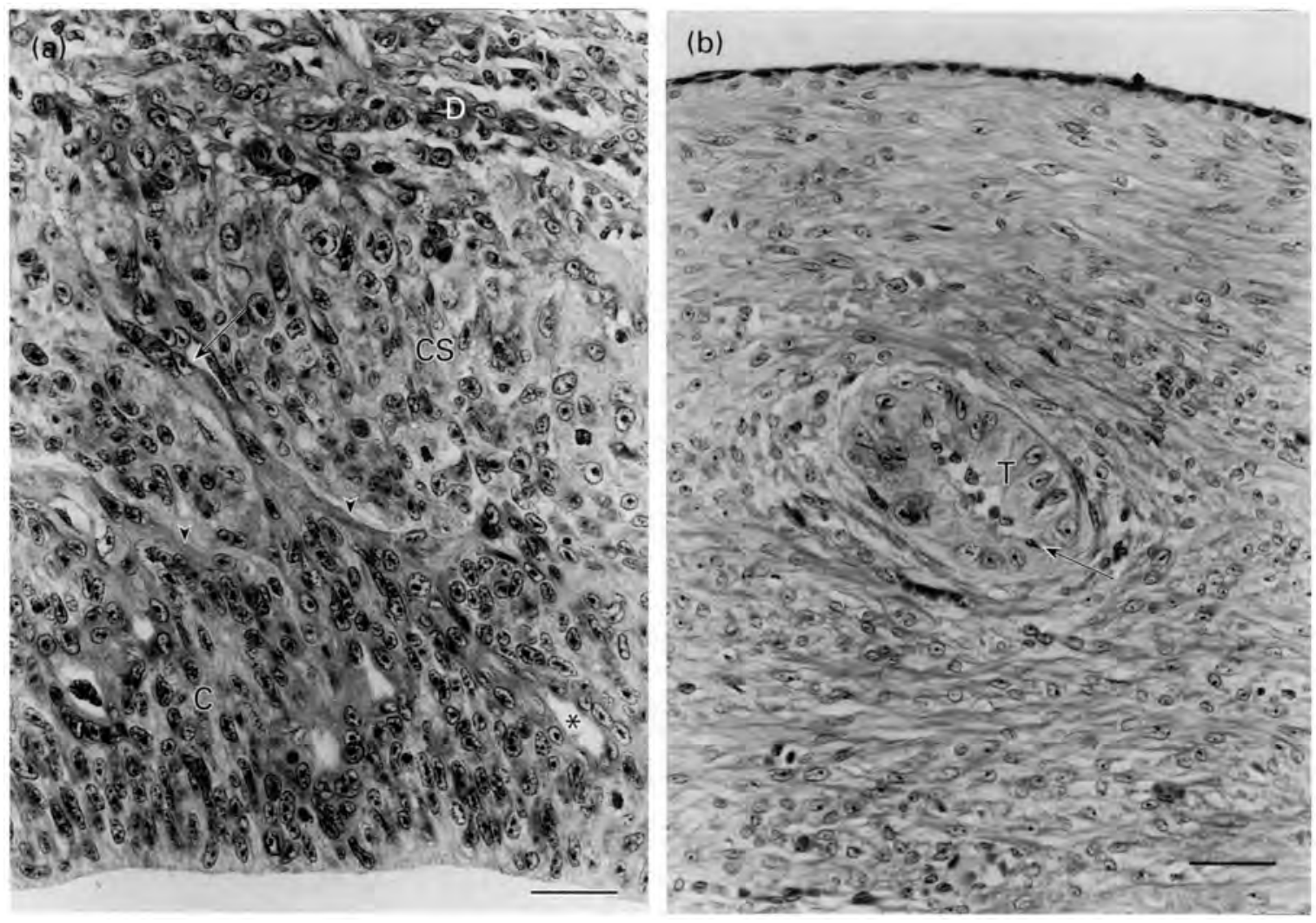

Fig. 3. Sections from gravid reproductive tracts of white-winged vampire bats, Dinemus youngi. (a) Section of developing placenta associated with an early implanted blastocyst. Syncytiotrophoblast lines the maternal vascular spaces $\left(^{*}\right)$ within the preplacenta and appears to be migrating away from its syncytial face (arrowheads) around a maternal blood vessel (arrow). (b) Section of myometrium from a uterus carrying an implanted blastocyst. Trophoblast has penetrated close to the serosal surface (top) via a subendothelial route within the wall of a maternal vessel. Endothelial cells (arrow) still line the lumen of the vessel. Both sections were stained with haematoxylin and eosin. C, cytotrophoblast within the preplacenta; CS, cytotrophoblastic shell; D, decidua basalis; T, trophoblast. Scale bars represent $30 \mu \mathrm{m}$.

some of these may be large and formed by the fusion of smaller masses. Despite the wide dispersal of trophoblast in Diaemus, it was never observed migrating by an endovascular route.

\section{Formation of dendritic processes by highly invasive trophoblast}

As pregnancy progressed, the highly invasive trophoblast in the myometrium, mesenteries and ovaries developed branching cytoplasmic processes that extended into adjacent tissues. These were relatively common in the tract carrying a $22 \mathrm{~mm}$ fetus, and were very abundant by late pregnancy (fetal size $\geq 28.0 \mathrm{~mm}$ ) (Figs $6 \mathrm{f}$ and $9 \mathrm{~d}$ ). In the myometrium, this frequently brought such processes close to many of the smooth muscle fibres. These processes were positive for cytokeratin and vimentin and negative for desmin. Particularly in the myometrium, it was easy to see that the bodies of these trophoblast cells were largely or completely perivascular. Although many of the highly invasive trophoblast cells developed cytokeratin-positive dendritic processes late in pregnancy, some trophoblast also appeared to extend similar processes into the decidua much earlier in gestation (Fig. 6a).

\section{Maternal vascular changes during pregnancy}

In view of the extensive trophoblastic invasion of the uterine wall and adjacent tissues via a perivascular route, it is important to note that the blood vessels serving the uterus also underwent substantial changes during pregnancy. These included dilatation of the vessels, some vascular smooth muscle hypertrophy, widespread intimal thickening in the arteries (Fig. 9a,b), fibrotic changes (most evident in postpartum tracts), and a significant increase in the amount of glycoproteins in the vessel walls (particularly the arteries). In some of the arterial vessels, there also appeared to be a loss of smooth muscle fibres from the tunica media. However, this may have been due to phenotypic alteration or dedifferentiation of these cells, which then became part of the thickened intima (N. K. Badwaik, J. J. Rasweiler IV and F. Muradali, unpublished).

\section{Discussion}

Some of the trophoblast that develops during pregnancy in Molossus and Dinemus is far more invasive than that observed in most other mammals. In Molossus, this trophoblast is cellular and is derived from the cytotrophoblastic shell 


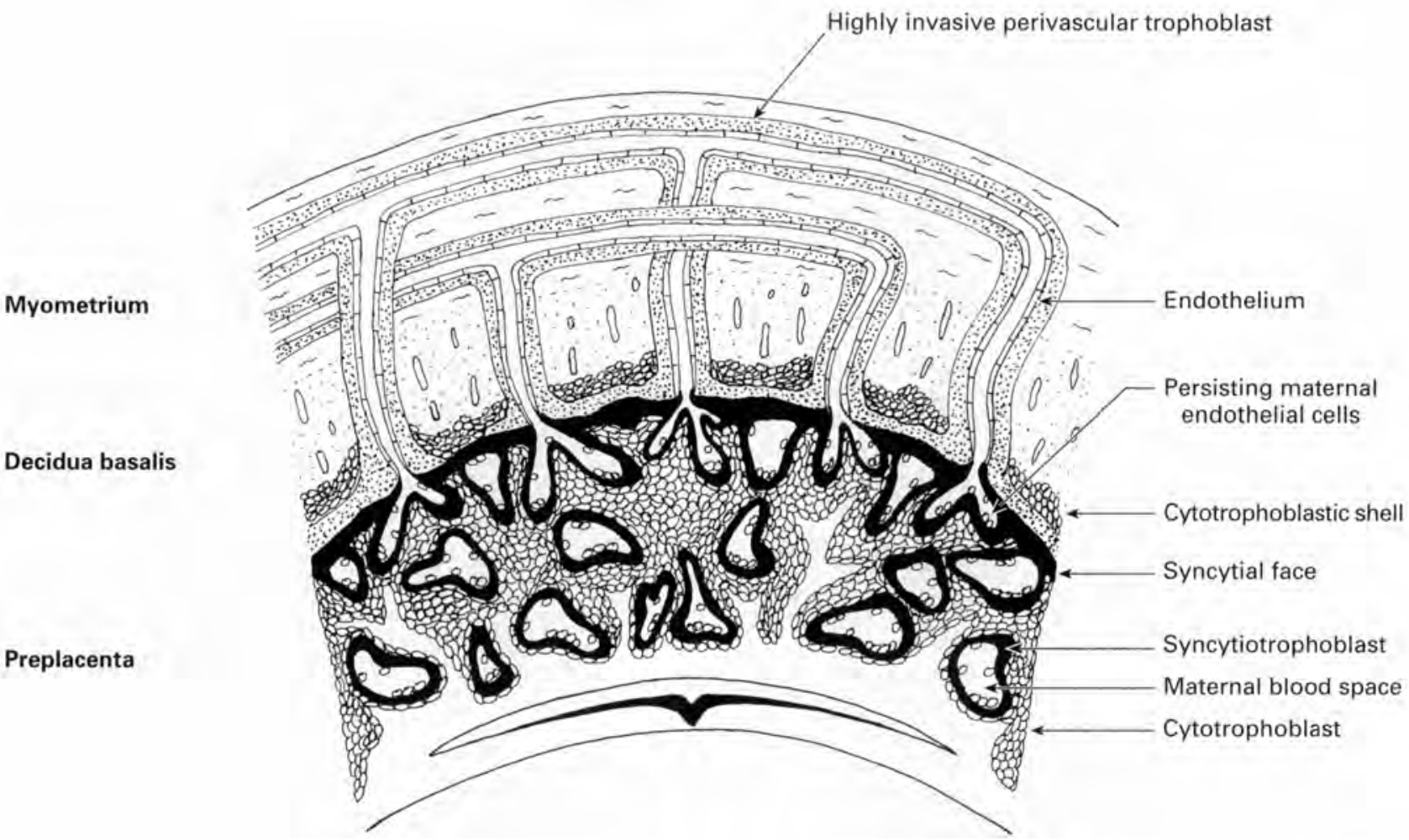

Fig. 4. Diagrammatic representation of the developing placenta and adjacent uterine wall in a white-winged vampire bat, Diaemus younti, carrying a primitive streak stage embryo. Highly invasive trophoblast appears to be released from the syncytial face of the preplacenta (chorionic placenta). It then migrates into the myometrium via a subendothelial route.

located along the base of the discoidal haemochorial placenta. This invasive cytotrophoblast preferentially penetrates the arterial vessels that serve the discoidal placenta via an interstitial (subendothelial) route.

In Diaemus, the highly invasive trophoblast is multinucleated and appears to arise from the syncytial face of the developing discoidal placenta. Further studies are required to clarify how this trophoblast is released and how large the multinucleated masses are. The non-mitotic syncytial face is apparently replenished by fusion of cytotrophoblast cells in the preplacenta with the syncytial face or with contiguous portions of the syncytiotrophoblast lining the placental labyrinth. Movement to the syncytial face may activate mesenchymal gene programmes, as syncytiotrophoblast in this region expresses considerable vimentin. In contrast, syncytiotrophoblast within the placenta does not contain immunocytochemically detectable levels of vimentin. Massive amounts of the highly invasive trophoblast of Diaemus invades the myometrium during early pregnancy via a subendothelial route along the maternal blood vessels. It does not exhibit an obvious preference for arterial or venous vessels.

The syncytial face is also rich in glycoproteins. These may represent either the result of abortive efforts by the syncytiotrophoblast to form an intrasyncytial lamina (as apparently exists in contiguous areas of the placental labyrinth) or intrasyncytial lamina left behind as trophoblastic masses are released from the syncytial face. Further studies are required at the ultrastructural level to clarify the processes that occur in this region.
The initial invasion beyond the endometrial-myometrial border in both Molossus and Diaemus occurs along the basal lamina of the endothelium lining the maternal vessels. This is perhaps not surprising because studies of placental development in Molossus suggest that maternal endothelial cells secrete factors that play an important role in controlling trophoblastic growth and differentiation, and that these may be incorporated, at least in part, into the basal lamina of the endothelial cells (Rasweiler, 1991a). Maternal endothelial cells may have similar roles in species that have intrasyncytial laminae in their placental barrier, for example Diaemus. Studies of the development of intrasyncytial lamina generally indicate that components of the endothelial cell basal lamina are initially incorporated into this layer, possibly for such morphogenetic reasons (Cukierski, 1987; Rasweiler, 1991a, 1993).

In Diaemus, some of the highly invasive trophoblast soon becomes multi-layered or migrates along the outside of trophoblast that had previously colonized the vessel walls. Extracellular matrix components secreted by the inner layers of trophoblast may function in a similar fashion to that suggested for the endothelial cell basal laminae and guide invasion by succeeding layers of trophoblast. No evidence for endovascular migration of highly invasive trophoblast was observed in either Molossus or Diaemus.

In these bats, trophoblast also penetrates the mesenteries of the reproductive tract, the ovaries and the oviducts via migration within the walls of the maternal blood vessels. This is the first report of non-cancerous trophoblastic invasion of the ovaries in mammals. The ultimate extent of 

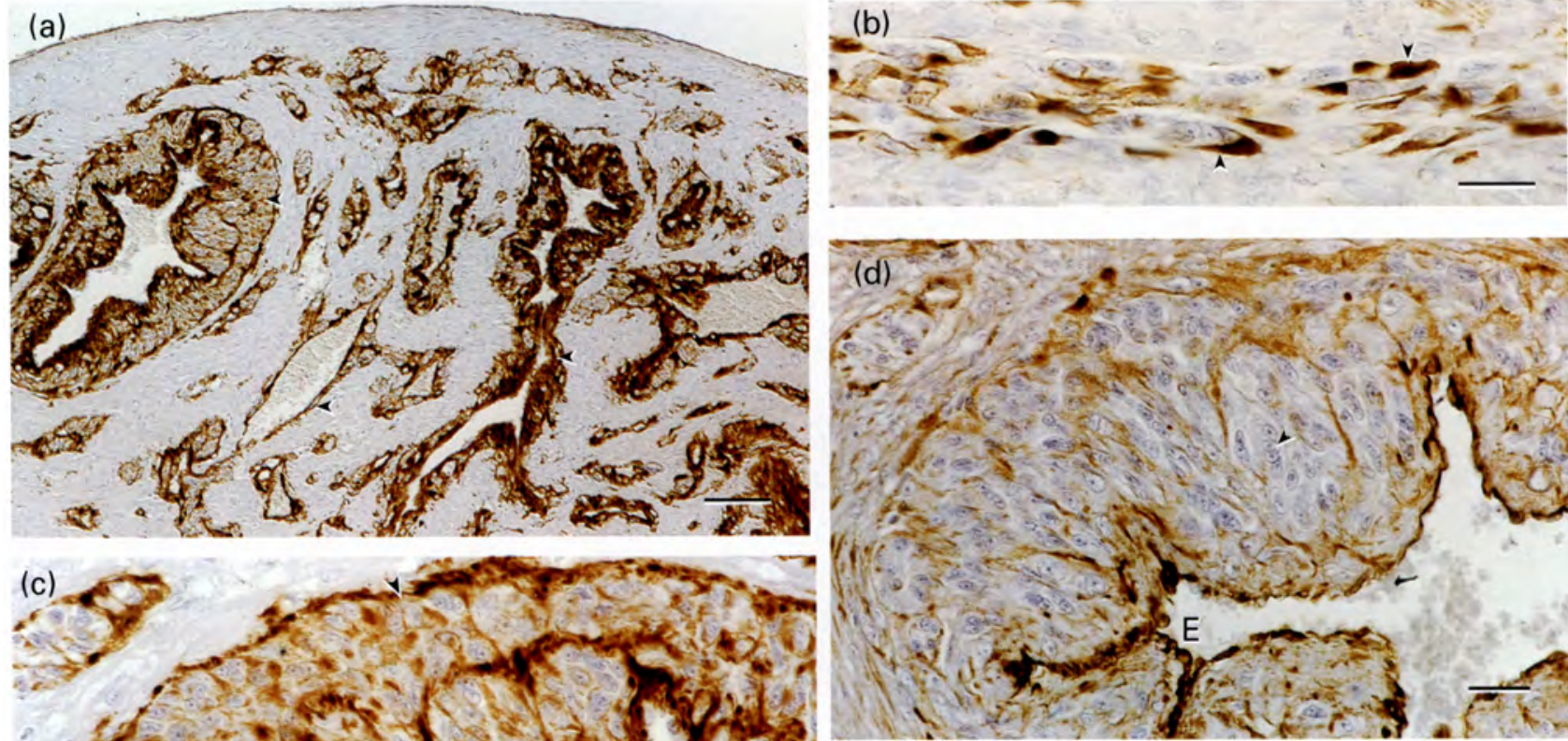

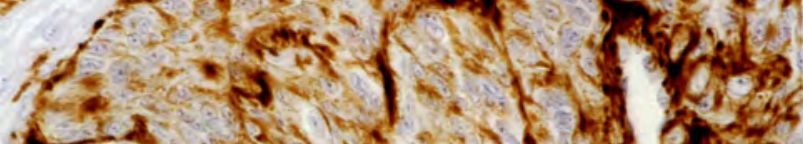

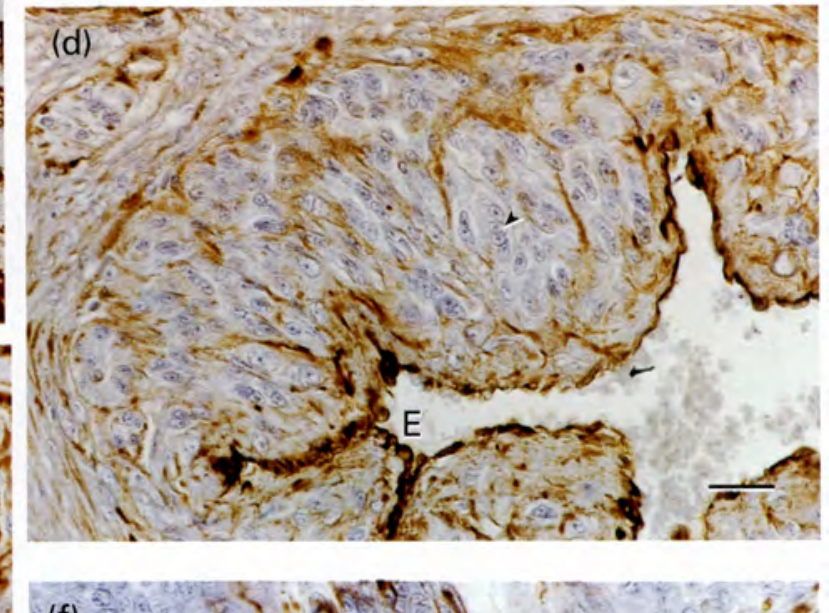

$(1+2) \leq 2)$

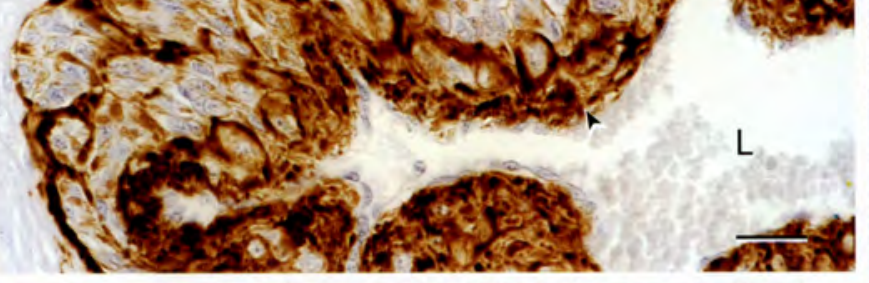

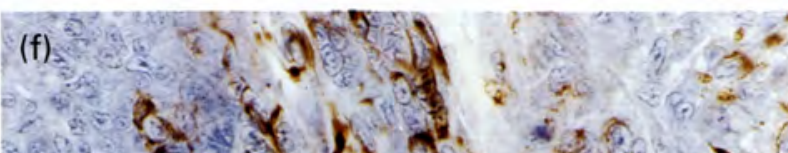

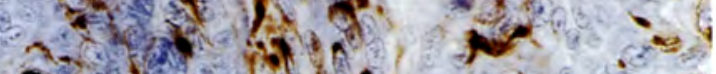

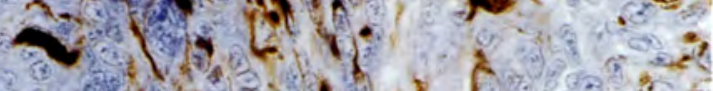

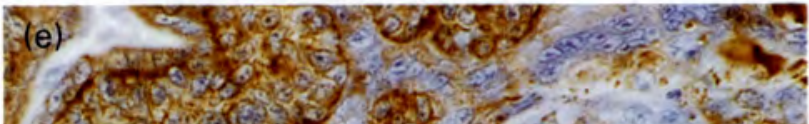

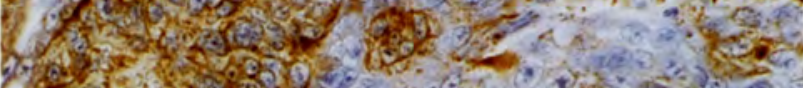
Q.

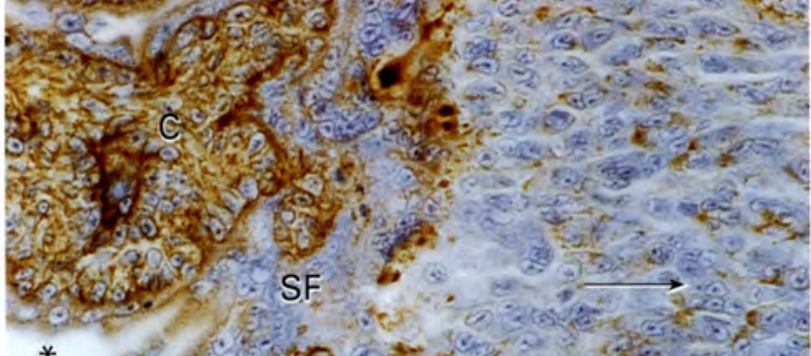

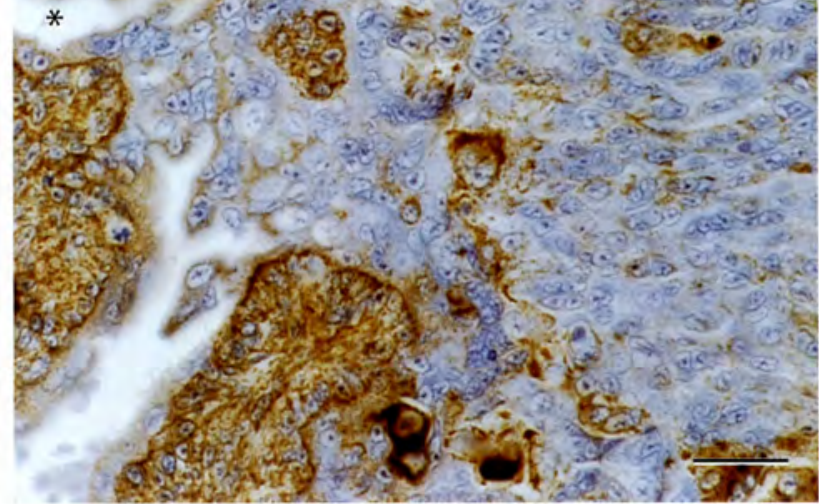
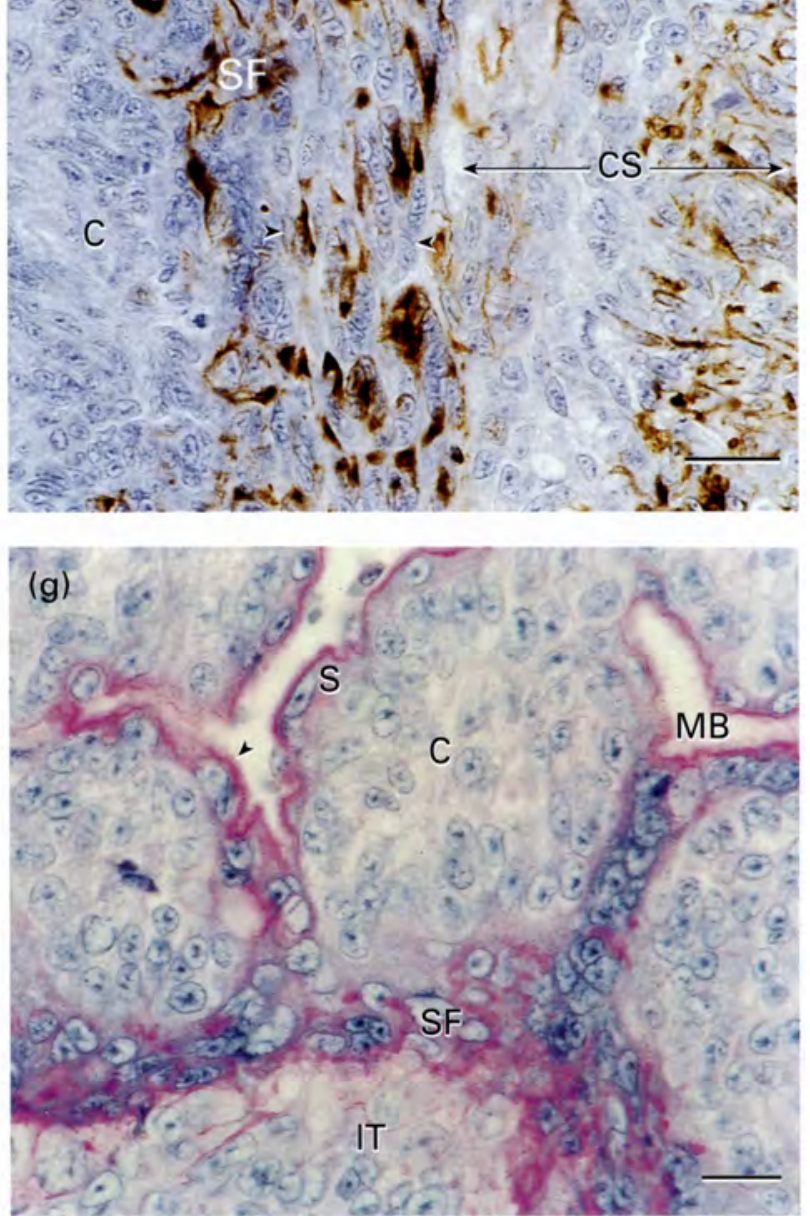
invasion of the maternal tissues could not be established for either species, as trophoblast was present in late pregnancy up to the points where the mesenteries were clipped at the time of dissection.

In view of this pronounced invasiveness, it is not surprising that the extraplacental trophoblast of both species expresses vimentin as well as cytokeratins. These cells must undergo an epithelial-mesenchymal transformation to migrate through the connective tissues and this is frequently associated with the initiation of vimentin expression (Hay, 1995; Hay and Zuk, 1995). Humans also have highly invasive trophoblast that originates from anchoring villi of the placenta. Immunocytochemical studies indicate that cytotrophoblast of these villi, the cytotrophoblastic shell, and the interstitial cytotrophoblast infiltrating the decidua and myometrium all express vimentin (Loke and Butterworth, 1987). The results of the present study show that humans can no longer be considered unique in the extent to which mesenchymal transformation of trophoblast occurs (Vicovac and Aplin, 1996). The obplacental giant cells of rabbits, which are thought to be of trophoblastic origin, also coexpress cytokeratins and vimentin (Blackburn et al., 1989). The trophoblast of guinea-pigs, which invades the mesometrium via interstitial routes, was found to be negative for vimentin (Nanaev et al., 1995).

Cytokeratin expression has been widely viewed as a marker for cells of epithelial origin (for example trophoblast), and vimentin as a marker for cells of mesenchymal origin (for example decidual cells). The results of the present study indicate that intermediate filament protein immunocytochemistry must be used with caution for the identification of trophoblast and decidual cells, particularly in exotic species. The co-expression of cytokeratins and vimentin was observed in the highly invasive trophoblast of both Diaemus and Molossus, as well as in the decidual giant cells of Molossus. Furthermore, the extent of expression of these intermediate filament proteins was contrary to expectations in some cell populations. Most notably, the syncytiotrophoblast lining the placental labyrinth of Diaemus late in pregnancy expressed very little cytokeratin. In addition, some decidual cells in this species expressed little vimentin (although they were strongly positive for desmin), whereas there was substantial expression of vimentin by highly invasive trophoblast in the same sections.

The absence of significant cytokeratin expression by the syncytiotrophoblast lining the placental labyrinth of Diaemus late in pregnancy is of interest because cytokeratins usually constitute much or all of the intermediate filaments that are part of the cytoskeleton in cells of epithelial origin. In addition, in the interhaemal barrier of the human placenta, both the syncytiotrophoblast and the cytotrophoblast react strongly with one of the same anti-cytokeratin antibody preparations (mix AE1/AE3) used in the present study (Daya and Sabet, 1991). The reason for this species difference is unknown. A similar differential expression of cytokeratins by the cytotrophoblast and syncytiotrophoblast has been observed in the placenta of another bat, Pteronotus parnellii (Badwaik and Rasweiler, 1998).

One of the functions of decidual cells is to control trophoblastic invasiveness (Bell, 1985; Loke and King, 1995). In Molossus (Rasweiler, 1990, 1991a) and Diaemus, the endometrial stroma undergoes pronounced decidualization during pregnancy. However, in both species, a population of highly invasive trophoblast cells manages to penetrate through the decidua, albeit via restricted perivascular pathways. In Diaemus, this takes place on a massive scale. The eventual extent of this invasion presumably depends on other factors: for example, the expression of proteinases and adhesion molecules may change with trophoblastic age or

Fig. 5. Sections from gravid reproductive tracts of white-winged vampire bats, Diaemus youngi. (a) Section of myometrium beneath the developing discoidal placenta in a uterus carrying a primitive streak stage embryo stained immunocytochemically for cytokeratins using antibody mix AE1/AE3 and counterstained lightly with haematoxylin. Abundant cytokeratin-positive trophoblast (arrowheads) is present in the walls of the maternal arterial and venous vessels. No uterine glands are present in this field. (b) Section of myometrium from a uterus carrying a somite stage embryo stained immunocytochemically for vimentin and lightly counterstained with haematoxylin. Multinucleated trophoblast cells (arrowheads) in the wall of a maternal blood vessel are positive for vimentin. (c) Higher power view of a maternal blood vessel in the section of myometrium shown in (a). A broad band of cytokeratin-positive trophoblast (between arrowheads) is present in the vessel wall. Note that the cytokeratin-negative endothelium still lines the lumen. (d) Section of myometrium adjacent to that shown in (c), stained immunocytochemically for vimentin and counterstained with haematoxylin. Note that many of the trophoblast cells are multinucleated (arrowhead), and that vimentin frequently has a distribution similar to that of cytokeratins in the trophoblast cells. The endothelial lining of the vessels is also positive for vimentin. (e) Section through the syncytial face of the developing chorioallantoic placenta associated with a primitive streak stage embryo stained immunocytochemically for cytokeratins with antibody mix AE1/AE3 and counterstained with haematoxylin. The syncytial face is continuous with, and stains similarly to, the syncytiotrophoblast lining maternal vascular spaces in the placental labyrinth $\left({ }^{*}\right)$. Cytotrophoblast within the placenta is much more reactive for cytokeratins. The right side of the figure shows elongated multinucleated masses of trophoblast apparently leaving the syncytial face in the direction shown by the arrow. (f) Section through the syncytial face of the placenta shown in (e), stained immunocytochemically for vimentin and counterstained with haematoxylin. Both the trophoblast in the syncytial face and the multinucleated masses of invasive trophoblast migrating away from it (between arrowheads) are positive for vimentin. Most of the invasive trophoblast shown appears to be migrating parallel to the syncytial face, towards major vessels near the centre of the placenta. In contrast, the cytotrophoblastic shell immediately adjacent to the invasive trophoblast contains little vimentin. Cytotrophoblast within the placenta was negative for vimentin. $(\mathrm{g})$ Section through the syncytial face of the placenta shown in (e) and (f), stained with periodic acid-Schiff (PAS) and haematoxylin. A glycoprotein-rich layer (arrowhead), which presumably represents an intrasyncytial lamina, is present near the luminal edge of the syncytiotrophoblast lining the maternal blood spaces. Masses of similarly stained material are abundant in the syncytiotrophoblast of the syncytial face. C, cytotrophoblast; CS, cytotrophoblastic shell; E, endothelial lining; IT, invasive trophoblast leaving the syncytial face; L, lumen of vessel; MB, maternal blood spaces; $\mathrm{S}$, syncytiotrophoblast; $\mathrm{SF}$, syncytial face. Scale bars represent (a) $100 \mu \mathrm{m},(\mathrm{b}-\mathrm{f}) 25 \mu \mathrm{m}$ and (g) $10 \mu \mathrm{m}$. 

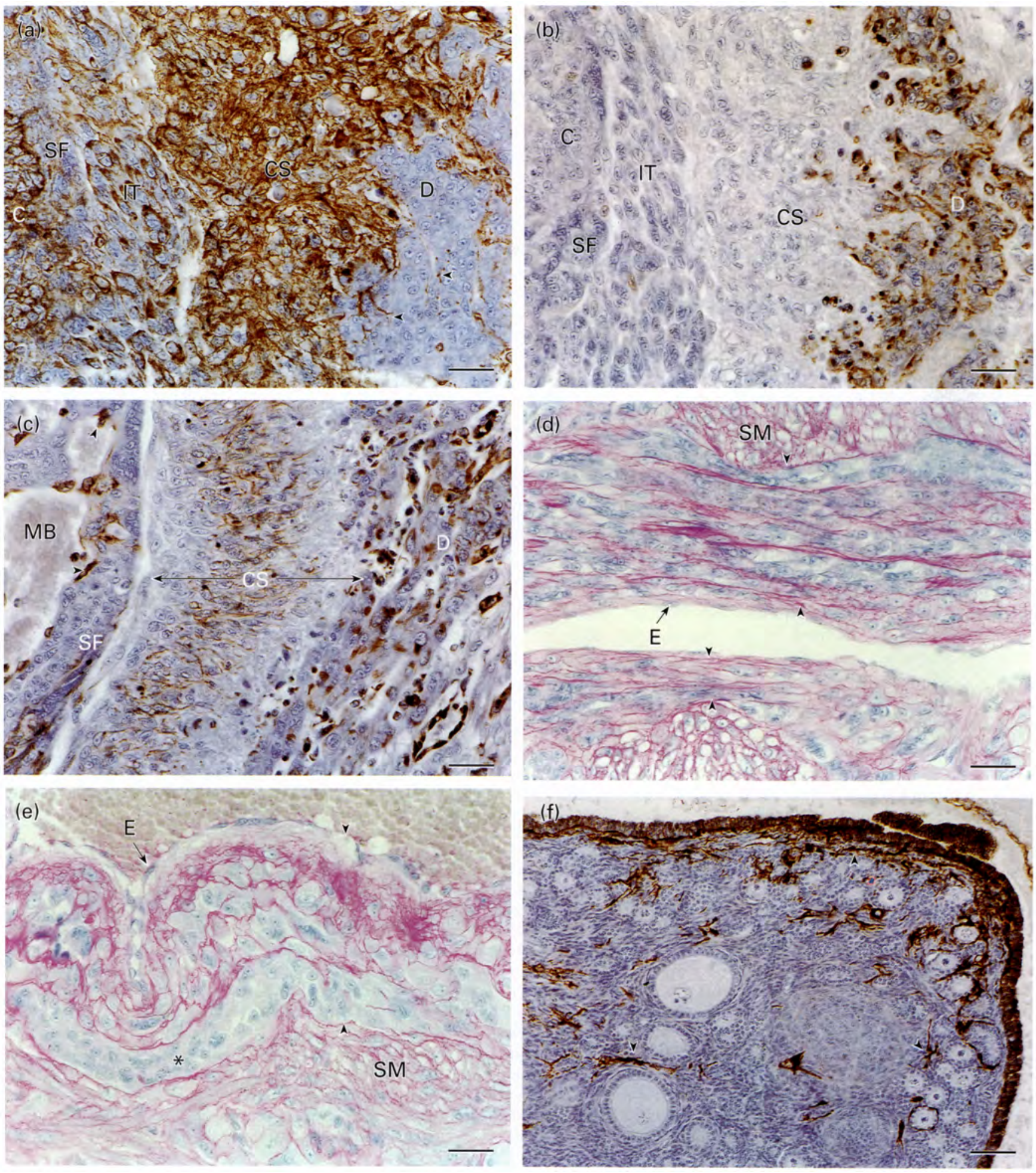

Fig. 6. Sections from gravid reproductive tracts of white-winged vampire bats, Diaemus youngi. (a) Section through the maternal side of a developing placenta associated with a somite stage embryo, stained immunocytochemically for cytokeratins with antibody mix AE1/AE3 and counterstained with haematoxylin. Areas reactive for cytokeratins include the cytotrophoblast of the placenta, the syncytial face of the placenta, the invasive multinucleated trophoblast leaving the placenta, and the cytotrophoblastic shell. The decidua basalis was negative for cytokeratin but was frequently penetrated by cytokeratin-positive processes of trophoblast (see arrowheads). (b) Section through the maternal side of a developing placenta associated with a somite stage embryo, stained immunocytochemically for desmin and counterstained with haematoxylin. In this field, strong desmin reactivity was limited to cells of the decidua basalis. (c) Section through the maternal side of a developing placenta associated with a somite stage embryo, stained immunocytochemically for vimentin and counterstained with haematoxylin. In this field, the decidual cells on the lateral side of the placenta contained substantial amounts of vimentin. Vimentin 


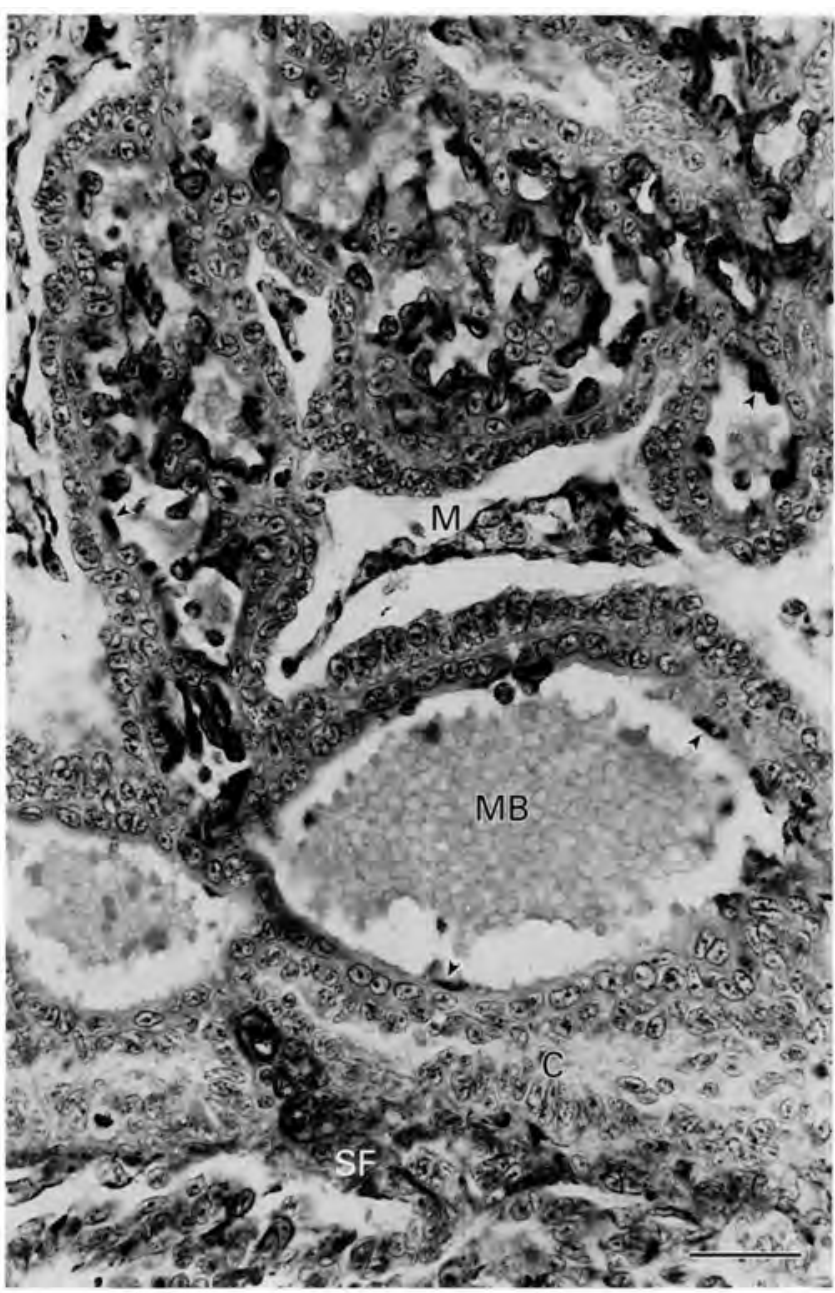

Fig. 7. Section through the maternal side of the placenta of a whitewinged vampire bat (Diaemus youngi) shown in Fig. $5 \mathrm{e}-\mathrm{f}$, stained immunocytochemically for vimentin and counterstained with haematoxylin. Only a few vimentin-positive maternal endothelial cells (arrowheads) were still present in the portion of the labyrinth closest to the syncytial face of the placenta. Rounded-up endothelial cells were much more abundant in portions of the labyrinth deeper within the placenta (upper half of figure). C, cytotrophoblast; $M$, mesoderm; MB, maternal blood space; $\mathrm{SF}$, syncytial face. Scale bar represents $25 \mu \mathrm{m}$.

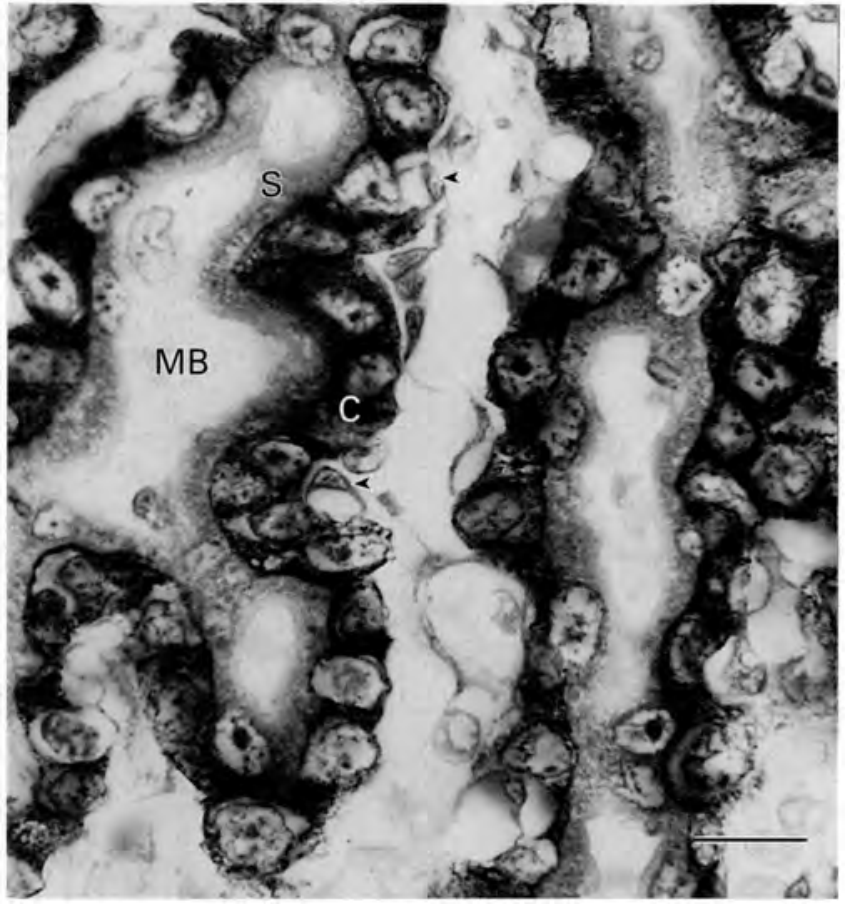

Fig. 8. Section through the chorioallantoic placenta serving a $22 \mathrm{~mm}$ fetus of a white-winged vampire bat (Dinemus youngi), stained immunocytochemically for cytokeratins with antibody mix AE1/AE3 and counterstained with haematoxylin. At this stage the maternal blood spaces are lined by syncytiotrophoblast, and persisting maternal endothelial cells were rarely observed. The syncytiotrophoblast exhibited appreciable staining only with haematoxylin (in contrast to the moderate cytokeratin reactivity of the syncytiotrophoblast shown in a younger placenta (Fig. 5e)), whereas the adjacent cytotrophoblast stained strongly for cytokeratins. The arrowheads denote fetal capillaries. C, cytotrophoblast; MB, maternal blood spaces; S, syncytiotrophoblast. Scale bar represents $10 \mu \mathrm{m}$.

differentiation; the production of growth factors, cytokines and proteinase inhibitors by non-decidual cells; and the nature of the extracellular matrix encountered by the trophoblast during the course of migration.

The populations of cytotrophoblast that become linked to, or extensively intermingled with, maternal endothelial cells

expression was less pronounced in decidual cells near the centre of the placenta. Some cells of the cytotrophoblastic shell also contained considerable amounts of vimentin. Only a little invasive trophoblast was associated with the syncytial face on this portion of the placenta. In addition, in contrast to other regions of the same placenta (Fig. 7), this section has only scattered maternal endothelial cells (at arrowheads) present in the maternal blood spaces. (d) Section of myometrium from a uterus carrying a primitive streak stage embryo stained with periodic acid-Schiff (PAS)-haematoxylin. Elongated multinucleated masses of trophoblast (between arrowheads) with associated PAS-positive glycoproteins can be seen in the wall of a maternal blood vessel. This is a near midsagittal section of the vessel, and the trophoblast is therefore really multilayered in the vessel wall. The lumen of this vessel was still lined by endothelial cells. (e) Section of the vessel shown in (d) within the myometrium, but further away from the developing placenta. A broad layer of trophoblast (between arrowheads) was present in the vessel wall. With the exception of a band on the periphery $\left(^{*}\right)$, this trophoblast was surrounded by an abundance of amorphous PAS-positive material. Note that the vessel still has an intact endothelial lining. Staining was with PAS-haematoxylin. (f) Section of ovary from a female carrying a $36.3 \mathrm{~mm}$ fetus (advanced pregnancy). This was stained immunocytochemically for cytokeratins with antibody mix AE1/AE3 and counterstained with haematoxylin. Many cytokeratin-positive trophoblast cells (arrowheads) are present in the ovarian stroma. These have attenuated branching processes similar to the invasive trophoblast in the myometrium of the same animal (Fig. 9d). The germinal epithelium was also positive for cytokeratin. C, cytotrophoblast; CS, cytotrophoblastic shell; D, decidua basalis; E, endothelial lining; IT, invasive multinucleated trophoblast; MB, maternal blood spaces; SF, syncytial face; SM, myometrial smooth muscle. Scale bars represent (a-e) $25 \mu \mathrm{m}$ and (f) $50 \mu \mathrm{m}$. 

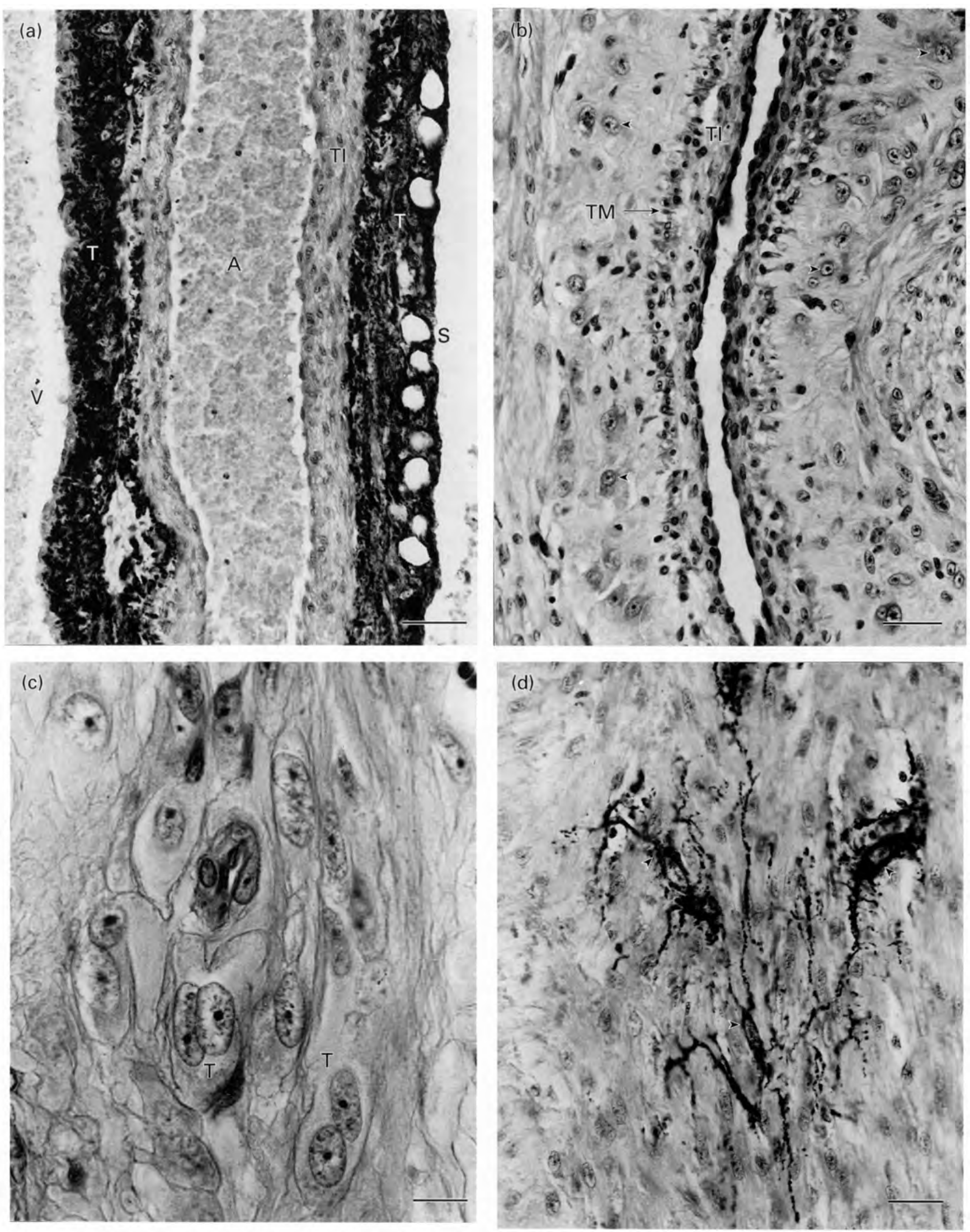

Fig. 9. Sections from reproductive tracts of white-winged vampire bats, Diaemus youngi. (a) Longitudinal sections of an artery and the adjacent wall of a vein in the broad ligament of a pregnant Dinemus carrying a $36.3 \mathrm{~mm}$ fetus. This slide was stained immunocytochemically for cytokeratins with antibody mix AE1/ AE3 and counterstained with haematoxylin. Cytokeratin-positive trophoblast is abundant in the walls of 
in the uteroplacental vessels of Molossus are also of interest. Most of these cytotrophoblast cells do not express immunocytochemically detectable levels of vimentin in contrast to the highly invasive extraplacental trophoblast. However, the intimate association between this cytotrophoblast and the endothelial cells suggests that they may express similar cell adhesion molecules. This has been observed in the cytotrophoblast cells that invade the spiral arterioles serving human and macaque placentae (Burrows et al., 1994; Blankenship and King, 1996; Blankenship and Enders, 1997b; Zhou et al., 1997a,b).

There is sufficient information about pregnancy in Molossus and Diaemus to enable suggestions regarding the functional significance of the highly invasive trophoblast to be made. Molossus develops two different chorioallantoic placentae: a diffuse endotheliochorial placenta that is prominent during mid-gestation, and a discoidal haemochorial placenta that becomes the major site of fetomaternal exchange during late gestation. The diffuse placenta is served by spiral arterioles along much of the length of the right uterine horn, and these carry much less blood when all of the maternal vascular tubules in this placenta atrophy. The discoidal placenta is supplied by vessels that develop from an unusual vascular tuft which forms after ovulation at the cranial end of the right horn. In early pregnancy, the largest vessels at the base of this tuft are small arterioles and venules. As gestation progresses, these are converted into much larger uteroplacental arteries and veins. These convey very little blood into the developing discoidal placenta until it actually begins to function, when they dilate greatly (Rasweiler, 1990, 1991a, 1992). Trophoblast appears to preferentially invade the myometrial and mesenteric segments of the arteries serving this placenta. This suggests that the trophoblast has a role in promoting dilatation of the vessels. Extravillous trophoblast that invades the uteroplacental arteries of guinea-pigs expresses nitric oxide synthase. It has been suggested that nitric oxide production by these cells may be responsible for pregnancyinduced physiological dilatation of these vessels (Nanaev et al., 1995).

Trophoblastic invasion of maternal tissues is much more extensive in Diaemus than in Molossus, with large numbers of trophoblast cells invading the myometrium, the mesenteries of the reproductive tract and, to a lesser extent, the ovaries and oviducts via a perivascular route. As the vessels serving the uterus are significantly remodelled and dilate greatly during pregnancy, this again suggests that the perivascular trophoblast is responsible for many of the changes. It is also possible that this trophoblast has an important local influence upon myometrial contractility and that this role changes as gestation progresses. In late pregnancy, this trophoblast becomes more highly branched and extends attenuated processes around many of the myometrial smooth muscle fibres. Alternatively, the development of these processes may simply reflect the adoption of an even more mesenchymal phenotype by the trophoblast after extended residence in the extracellular matrix of the perivascular connective tissue (see Greenburg and Hay, 1982, 1986, 1988). In humans, a population of branching cytokeratin 17-positive extravillous trophoblast cells has been observed in the walls of the uteroplacental arteries, but its physiological significance is unknown (Pröll et al., 1997).

Although trophoblastic invasion of the ovaries was observed in both Molossus and Diaemus, this was relatively limited compared with that observed in adjacent tissues (for example the mesenteries of the reproductive tract in Diaemus). This suggests that the presence of trophoblast in the ovaries primarily reflects its invasiveness and is of limited significance in influencing ovarian function. However, it is possible that trophoblast within the ovaries and around the arteries serving the ovaries exerts a local influence on ovarian function.

Highly invasive trophoblast has also been observed in the short-tailed fruit bat, Carollia perspicillata, which, like Diaemus, belongs to the family Phyllostomidae. However, in Carollia, the highly invasive trophoblast is associated with altered trophoblastic differentiation (for example, the retarded formation of both polarized cytotrophoblast and syncytiotrophoblast within the preplacenta) and delayed development of the conceptus. In contrast, highly invasive trophoblast is absent or uncommon in captive-bred Carollia carrying normal or near-normal pregnancies at least up to day 60 after mating (J. J. Rasweiler IV and N. K. Badwaik, unpublished). In Carollia, delayed development occurs seasonally in the wild and in response to stress in captivity (Rasweiler and Badwaik, 1997). It also occurs under natural conditions in other species of phyllostomid bats (Artibeus jamaicensis and Macrotus californicus; Bradshaw, 1962; Fleming, 1971; Bleier, 1975).

Whether the appearance of highly invasive trophoblast is associated with the occurrence of a period of delayed development during pregnancy in Diaemus remains to be determined. The present study indicates that there is some synchronization of female reproductive activity in the wild (Table 1). However, Diaemus feeds on the blood of birds and

both vessels. The artery did not have a well defined tunica media, but had a thickened tunica intima that is typical of arterial vessels serving the uterus in advanced pregnancy and soon after parturition. (b) Longitudinal section of artery in the myometrium of a postpartum uterus (maximum diameter $=7.0 \mathrm{~mm}$ ) stained with haematoxylin and eosin. Abundant trophoblast (arrowheads) is present in the tunica adventitia and adjacent tissues. The tunica intima of this vessel was also thickened. (c) Tangential section of the tunica adventitia of the same artery shown in (b), stained with periodic acid-Schiff (PAS)-haematoxylin. This contains trophoblastic masses that are surrounded by an amorphous layer of PAS-positive material and are often multinucleated. These masses generally continued into adjacent sections, and it was difficult to determine their full extent. Cells with these characteristics also expressed cytokeratins. (d) Section of myometrium from a uterus carrying a $36.3 \mathrm{~mm}$ fetus (advanced pregnancy) stained immunocytochemically for cytokeratins with antibody mix AE1/AE3 and counterstained with haematoxylin. The abundant trophoblast (arrowheads) in this region have long branching processes which extend in between many of the myometrial smooth muscle fibres that are present throughout the field. A, artery; S, serosal surface of mesentery; $\mathrm{T}$, trophoblast; TI, tunica intima, TM, tunia media; $V$, vein. Scale bars represent (a) $50 \mu \mathrm{m}$, (b) $30 \mu \mathrm{m}$, (c) $10 \mu \mathrm{m}$ and (d) $25 \mu \mathrm{m}$. 
mammals (Greenhall, 1988), and this should be available throughout the year in the humid lowland tropics of the New World. The possible adaptive significance of such synchronization, or of any seasonal delay in conceptus development, is therefore unclear. As Diaemus frequently breeds again soon after giving birth, it is possibile that a period of delayed development might be advantageous during lactation. It must be emphasized that while this could be related to the development of highly invasive trophoblast (as in Carollia), the available evidence suggests that a major role of this population of trophoblast in Diaemus is to alter the function of blood vessels serving the gravid tract. Although this trophoblast extends attenuated processes into much of the myometrium late in pregnancy, it is not yet clear whether these have any local influence upon myometrial function.

The authors are grateful to S. Williams and the staff of the Antirabies Unit, Ministry of Agriculture, Lands and Food Production, for assistance in this work. Thanks also go to the staff of the Department of Zoology, University of the West Indies, St Augustine, Trinidad, for their generous help and for the use of departmental facilities during some of the field work required for this study. This research has been supported by the Department of Obstetrics and Gynecology, Cornell University, and National Institutes of Health Grants HD-17739 and 28592.

\section{References}

Badwaik NK and Rasweiler JJ, IV (1998) The interhaemal barrier in the chorioallantoic placenta of the greater mustache bat, Pteronotus parnellii, with observations on amplification of its intrasyncytial lamina Placenta 19 391-401

Badwaik NK, Rasweiler JJ, IV and Oliveira SF (1997) Formation of reticulated endoderm, Reichert's membrane, and amniogenesis in blastocysts of captive-bred, short-tailed fruit bats, Carollia perspicillata. Anatomical Record 247 85-101

Bell SC (1985) Comparative aspects of decidualization in rodents and humans: cell types, secreted products and associated function. In Implantation of the Human Embryo pp 71-122 Eds RG Edwards, JM Purdy and PC Steptoe. Academic Press, London

Björkman NH and Wimsatt WA (1968) The allantoic placenta of the vampire bat (Desmodus rotundus murinus): a reinterpretation of its structure based on electron microscopic observations Anatomical Record 162 83-98

Blackburn DG, Osteen KG, Winfrey VP and Hoffman LH (1989) Obplacental giant cells of the domestic rabbit: development, morphology, and intermediate filament composition Journal of Morphology 202 185-203

Blankenship TN and Enders AC (1997a) Trophoblast cell-mediated modifications to uterine spiral arteries during early gestation in the macaque Acta Anatomica 158 227-236

Blankenship TN and Enders AC (1997b) Expression of platelet-endothelial cell adhesion molecule-1 (PECAM) by macaque trophoblast cells during invasion of the spiral arteries Anatomical Record 247 413-419

Blankenship TN and King BF (1996) Macaque intra-arterial trophoblast and extravillous trophoblast of the cell columns and cytotrophoblastic shell express neural cell adhesion molecule (NCAM) Anatomical Record 245 $525-531$

Blankenship TN, Enders AC and King BF (1993a) Trophoblastic invasion and the development of uteroplacental arteries in the macaque: immunohistochemical localization of cytokeratins, desmin, type IV collagen, laminin and fibronectin Cell and Tissue Research 272 227-236

Blankenship TN, Enders AC and King BF (1993b) Trophoblastic invasion and modifications of uterine veins during placental development in macaques Cell and Tissue Research 274 135-144

Bleier WJ (1975) Early embryology and implantation in the California leafnosed bat, Macrotus californicus. Anatomical Record 182 237-254

Bonilla H de and Rasweiler JJ, IV (1974) Breeding activity, preimplantation development, and oviduct histology of the short-tailed fruit bat, Carollia, in captivity Anatomical Record 179 385-404

Bradshaw GVR (1962) Reproductive cycle of the California leaf-nosed bat, Macrotus californicus. Science 136 645-646

Brosens I, Dixon HG and Robertson WD (1979) Fetal growth retardation and the arteries of the placental bed British Journal of Obstetrics and Gynaecology $84656-663$

Burrows TD, King A and Loke YW (1994) Expression of adhesion molecules by endovascular trophoblast and decidual endothelial cells: implications for vascular invasion during implantation Placenta 15 21-33

Carpenter SJ (1982) Trophoblast invasion and alteration of mesometrial arteries in the pregnant hamster: light and electron microscopic observations Placenta 3 219-242

Cukierski MA (1987) Synthesis and transport studies of the intrasyncytial lamina: an unusual placental basement membrane in the little brown bat, Myotis lucifugus. American Journal of Anatomy 178 387-409

Daya D and Sabet L (1991) The use of cytokeratin as a sensitive and reliable marker for trophoblastic tissue American Journal of Clinical Pathology 95 137-141

DeWolf RC, DeWolf-Peeters C, Brosens I and Robertson WB (1980) The human placental bed: electron microscopic study of trophoblastic invasion of spiral arteries American Journal of Obstetrics and Gynecology 137 58-70

DeWolf F, Brosens I and Robertson WB (1982) Ultrastructure of uteroplacental arteries Contributions to Gynecology and Obstetrics $986-99$

Enders AC and Wimsatt WA (1968) Formation and structure of the hemodichorial chorio-allantoic placenta of the bat (Myotis lucifugus lucifugus) American Journal of Anatomy 122 453-490

Fleming TH (1971) Artibeus jamaicensis: delayed embryonic development in a neotropical bat Science 171 402-404

Gerretsen G, Juisjes HJ and Elema JD (1981) Morphological changes of the spiral arteries in the placental bed in relation to pre-eclampsia and fetal growth retardation British Journal of Obstetrics and Gynaecology 88 876-881

Goodwin GG and Greenhall AM (1961) A review of the bats of Trinidad and Tobago Bulletin of the American Museum of Natural History 122 187-302

Greenburg G and Hay ED (1982) Epithelia suspended in collagen gels can lose polarity and express characteristics of migrating mesenchymal cells Journal of Cell Biology 95 333-339

Greenburg G and Hay ED (1986) Cytodifferentiation and tissue phenotype change during transformation of embryonic lens epithelium to mesenchyme-like cells in vitro. Developmental Biology 115 363-379

Greenburg G and Hay ED (1988) Cytoskeleton and thyroglobulin expression change during transformation of thyroid epithelium to mesenchyme-like cells Development 102 605-622

Greenhall AM (1988) Feeding behaviour. In Natural History of Vampire Bats pp 111-132 Eds AM Greenhall and U Schmidt. CRC Press, Boca Raton, FL

Hay ED (1995) An overview of epithelio-mesenchymal transformation Acta Anatomica 154 8-20

Hay ED and Zuk A (1995) Transformation between epithelium and mesenchyme: normal, pathological and experimentally induced American Journal of Kidney Diseases 26 678-690

Hustin JE, Jauniaux E and Schaaps JP (1990) Histological study of the materno-embryonic interface in spontaneous abortions Placenta 11 477-486

Khong TY and Sawyer IH (1991) The human placental bed in health and diseases Reproduction Fertility Development 3 373-377

Khong TY, DeWolf F, Robertson WB and Brosens I (1986) Inadequate maternal vascular response to placentation in pregnancies complicated by pre-eclampsia and by small-for-gestational age infants British Journal of Obstetrics and Gynaecology 93 1049-1059

Loke YW and Butterworth BH (1987) Heterogeneity of human trophoblast populations. In Immunoregulation and Fetal Survival pp 197-209 Eds TJ Gill and TG Wegmann. Oxford University Press, New York

Loke YW and King A (1995) Human Implantation. Cell Biology and Immunology Cambridge University Press, Cambridge

Nanaev A, Chwalisz K, Frank H-G, Kohnen G, Hegele-Hartung and Kaufmann P (1995) Physiological dilation of uteroplacental arteries in the guinea pig depends on nitric oxide synthase activity of extravillous trophoblast Cell and Tissue Research 282 407-421

Novacek MJ and Wyss AR (1986) Higher-level relationships of the recent eutherian orders: morphological evidence Cladistics 2 257-287

Pijnenborg R (1991) Uteroplacental ischemia and hypertensive disorders of pregnancy British Journal of Obstetrics and Gynaecology 98 648-655

Pijnenborg R (1996) The placental bed Hypertension in Pregnancy 15 7-23

Pijnenborg R, Robertson WB, Brosens I and Dixon G (1981) Review article: 
trophoblast invasion and the establishment of haemochorial placentation in man and laboratory animals Placenta 2 71-92

Pijnenborg R, Anthony J, Davey DA, Rees A, Tiltman A, Vercruysse L and Assche Van A (1991) Placental bed spiral arteries in the hypertensive disorders of pregnancy British Journal of Obstetrics and Gynaecology 98 $648-655$

Pijnenborg R, Hooghe TD, Vercruysse $L$ and Bambra C (1996) Evaluation of trophoblast invasion in placental bed biopsies of the baboon, with immunohistochemical localisation of cytokeratin, fibronectin and laminin Journal of Medical Primatology 25 272-281

Pröll J, Blaschitz A, Hartmann M, Thalhamer J and Dohr G (1997) Cytokeratin 17 as an immunohistochemical marker for intramural cytotrophoblast in human first trimester uteroplacental arteries Cell and Tissue Research 288335-343

Rasweiler JJ, IV (1972) Reproduction in the long-tongued bat, Glossophaga soricina. I. Preimplantation development and histology of the oviduct Journal of Reproduction and Fertility 31 249-262

Rasweiler JJ, IV (1974) Reproduction in the long-tongued bat, Glossophaga soricina. II. Implantation and early embryonic development American Joumal of Anatomy 139 1-36

Rasweiler JJ, IV (1977) Preimplantation development, fate of the zona pellucida, and observations on the glycogen-rich oviduct of the little bulldog bat, Noctilio albiventris. American Journal of Anatomy 150 269-300

Rasweiler JJ, IV (1987) Prolonged receptivity to the male and the fate of the spermatozoa in the female black mastiff bat, Molossus ater. Journat of Reproduction and Fertility 79 643-654

Rasweiler JJ, IV (1990) Implantation, development of the fetal membranes, and placentation in the captive black mastiff bat, Molossus ater. American Journal of Anatomy 187 109-136

Rasweiler JJ, IV (1991a) Development of the discoidal hemochorial placenta in the black mastiff bat, Molossus ater: evidence for a role of maternal endothelial cells in the control of trophoblastic growth American Journal of Anatomy 191 185-207

Rasweiler JJ, IV (1991b) Spontaneous deciđual reactions and menstruation in the black mastiff bat, Molossus ater. Americal Journal of Anatomy 191 1-22

Rasweiler JJ, IV (1992) Reproductive biology of the female black mastiff bat, Molossus ater. In Reproductive Biology of South American Vertebrates pp 262-282 Ed. WC Hamlett. Springer- Verlag, New York

Rasweiler JJ, IV (1993) Pregnancy in Chiroptera Journal of Experimental Zoology 266 495-513

Rasweiler JJ, IV and Badwaik NK (1996) Unusual aspects of inner cell mass formation, endoderm differentiation, Reichert's membrane development and amniogenesis in the lesser bulldog bat, Noctilio albiventris. Anatomical Record 246 293-304

Rasweiler JJ, IV and Badwaik NK (1997) Delayed development in the shorttailed fruit bat, Carollia perspicillata. Journal of Reproduction and Fertility 1097-20

Sheppard BL and Bonnar J (1988) The maternal blood supply to the placenta in pregnancy complicated by intrauterine fetal growth retardation Trophoblast Research 3 69-81

Vicovac L and Aplin JD (1996) Epithelial-mesenchymal transition during trophoblast differentiation Acta Anatomica 156 202-216

Winter M and Coen C (1997) Lure of the vampires Bats 15 7-10

Zhou Y, Fisher SJ, Janatpour M, Genbacev $O$, Dejana E, Wheelock M and Damsky CH (1997a) Human cytotrophoblasts adopt a vascular phenotype as they differentiate. A strategy for successful endovascular invasion? Journal of Clinical Investigation 99 2139-2151

Zhou Y, Damsky CH and Fisher SJ (1997b) Pre-eclampsia is associated with failure of human cytotrophoblasts to mimic a vascular adhesion phenotype. One cause of defective endovascular invasion in this syndrome? Journal of Clinical Investigation 99 2152-2164 